\title{
Recent developments in genetics and medically assisted reproduction: from research to clinical applications
}

\author{
J.C. Harper ${ }^{1} \cdot$ K. Aittomäki $i^{2}$ P. Borry ${ }^{3}$ - M.C. Cornel $\mathbb{1}^{4} \cdot$ G. de Wert ${ }^{5} \cdot$ W. Dondorp $\mathbb{1}^{5} \cdot$ J. Geraedts ${ }^{6}$ L. Gianaroli ${ }^{7}$.

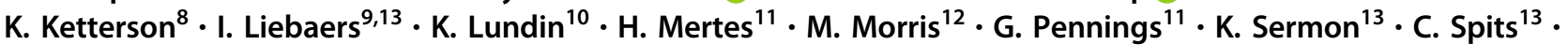 \\ S. Soini ${ }^{14} \cdot$ A.P.A. van Montfoort ${ }^{15} \cdot$ A. Veiga ${ }^{16,17} \cdot$ J.R. Vermeesch ${ }^{18} \cdot$ S. Viville ${ }^{19,20} \cdot$ M. Macek Jr. ${ }^{21}$ on behalf of the \\ European Society of Human Reproduction and Embryology and European Society of Human Genetics
}

Received: 23 April 2017 / Accepted: 14 September 2017 / Published online: 4 December 2017

(c) The Author(s) 2018. This article is published with open access

\begin{abstract}
Two leading European professional societies, the European Society of Human Genetics and the European Society for Human Reproduction and Embryology, have worked together since 2004 to evaluate the impact of fast research advances at the interface of assisted reproduction and genetics, including their application into clinical practice. In September 2016, the expert panel met for the third time. The topics discussed highlighted important issues covering the impacts of expanded carrier screening, direct-to-consumer genetic testing, voiding of the presumed anonymity of gamete donors by advanced genetic testing, advances in the research of genetic causes underlying male and female infertility, utilisation of massively parallel sequencing in preimplantation genetic testing and non-invasive prenatal screening, mitochondrial replacement in human oocytes, and additionally, issues related to cross-generational epigenetic inheritance following IVF and germline genome editing. The resulting paper represents a consensus of both professional societies involved.
\end{abstract}

Keywords Assisted reproductive technology $\cdot$ Epigenetics $\cdot$ Expanded carrier screening $\cdot$ Gamete donor anonymity $\cdot$ Germline genome editing $\cdot$ Female infertility $\cdot$ Male infertility $\cdot$ Mitochondrial replacement therapy $\cdot$ Non-invasive prenatal testing $\cdot$ Preimplantation genetic testing

\section{Introduction}

The two leading European professional societies in the field of assisted reproduction and medical genetics, the European Society of Human Genetics (ESHG) [1] and the European Society for Human Reproduction and Embryology (ESHRE) [2], have been working together since 2004 to evaluate the impact of the rapid progress of research and diagnostic technologies at the interface of assisted

This article is simultaneously published in Human Reproduction Open, pp. 1-20 2017 10.1093/hropen/hox015

This article represents developments presented at the Third meeting of ESHRE.eu and ESHG.org to discuss the interface between genetics and ART', 20-21 September 2016, Amsterdam, The Netherlands.

M. Macek Jr.

milan.macek.jr@1fmotol.cuni.cz

Extended author information available on the last page of the article reproduction and medical/molecular genetics. Previously, the outcomes of the two consensus meetings have been published [3, 4] in both society journals. The interdisciplinary expert group (further referred to in this paper as 'the panel') co-opted several new members and met for the third time in Amsterdam (21-22 September 2016).

Recently, there have been many research developments in the field of genomics, comprising mainly the ongoing transition from traditional 'monogenic genetics' towards comprehensive testing of the human genome by integrating massively parallel sequencing (MPS; or synonym 'next generation sequencing') approaches, together with advanced bioinformatics. Currently, it is possible to elucidate the entire single nucleotide-(SNV), copy number-(CNV) and structural variation (SV) of the human genome, i.e., beyond the original medical indication for which a patient (together with his or her family) was referred for genetic testing. These technological advances are being reflected in expanded carrier screening (ECS), voiding of gamete donor anonymity, preimplantation genetic testing (PGT) and noninvasive prenatal testing (NIPT), and in our understanding 
of the underlying causes of male and female infertility. Likewise, issues related to mitochondrial replacement in human oocytes and to cross-generational epigenetic inheritance or germline genome editing (GGE) technologies are gradually creating paradigm shifts in the field of assisted reproductive technology (ART). Therefore, the panel mainly focused on the aforementioned selected topics, which are currently being or are likely to be introduced into clinical practice.

Recently, transnational registry data provided evidence that the number of ART cycles in Europe is gradually increasing [5], with more than 640,000 cycles reported in 2012, making a growing contribution to the overall birth rate in many nations in Europe and beyond. The unprecedented complexity of generated research data and the fast (and often hurried) implementation of new technologies into the fields of assisted reproduction as well as of reproductive genetics render the translation of research results into clinical practice challenging. Therefore, due to the increasing population impact of ART and fast developments in research, the introduction both of novel diagnostics [6] and therapies into routine ART clinical practice requires prudence and evidence [7].

It also needs to be acknowledged that there is a blurred boundary between research and its clinical application. Medical and legal liability issues may also arise if the roles and responsibilities of different actors at different stages of translation of research results are not clearly established. Genetic counselling has become increasingly important for patients with various disorders associated with infertility and for future parents to make informed reproductive choices.

The aim of the current consensus paper is to outline the latest developments in ART and genetics/genomics, including their practical implications for clinical management of patients with genetic risks and/or infertility.

\section{ECS in preconception- and gamete donor contexts}

An increasing number of preconception carrier tests for autosomal recessive (AR) diseases have become available for couples who want to achieve a pregnancy. Initially, carrier testing was developed for AR diseases that were frequent in specific ethnic groups (for example, Tay-Sachs disease in Ashkenazi Jews, hemoglobinopathies in Mediterranean and African populations and cystic fibrosis in European-derived populations). Various professional societies have recommended preconception carrier testing in high-risk populations (American College of Obsetrics and Gynecology Committee, 2015 [8]) and the American College of Medical Genetics and Genomics 2015 [9, 10]. Given the technological advances in the field of genetic testing, panels for ECS have become broadly available, offering parallel analysis of disease-associated variants in multiple genes, for individuals or couples regardless of their ancestry. A number of such tests are now provided as commercial products, and even within a direct-to-consumer (DTC) setting [11, 12].

The primary objective of ECS in individuals or couples should be to inform them of possible genetic disease risks for their future offspring and their reproductive options in order to foster autonomous reproductive choices [10]. Although the secondary outcome of broadly offered ECS schemes may decrease the frequency of a target condition, as reported, for example, in cystic fibrosis [13], its primary goal is to ensure reproductive autonomy in tested couples. Therefore, non-directive counselling in a pre- and post-test setting is of utmost importance within this context [14]. Still, complex questions may arise if a 'positive' infertile carrier couple would request ART treatment, while rejecting PGD. Would it, then, be morally acceptable or even morally obliged for medical professionals to get involved, given their responsibility to take account of the welfare of the possible future child, to withhold access to assisted reproduction? [15].

Readily available ECS requires a proper implementation strategy [10]. In this regard relevant questions need to be answered first, i.e., what are the responsibilities of healthcare professionals who see couples before pregnancy; which genes and diseases should be tested for; which population groups should be targeted; who will pay for ECS; are couples aware that de novo disease-associated variants are not accounted for and that some disease-associated variants (for example, $\mathrm{CNV}, \mathrm{SNV}$ ) in multiple AR conditions are not examined due to the methodology used and its inherent technical limitations?

To ensure successful implementation of populationbased ECS, efforts should be made to increase knowledge about genetic disease (i.e., not only on AR disorders) within primary care, among gynaecologists, obstetricians and the general public, in order to create appropriate awareness and address personal benefits of screening in a non-directive manner [16]. Such information should include residual risks of tested diseases and age specific risks of de novo diseaseassociated variants [17]. Importantly, dominant de novo mutations represent a non-negligible (1-2\%) cause of genetic disorders [11, 18].

The ESHG has recommended that in ECS panels 'priority should be given to carrier screening panels that include (a comprehensive set of) severe childhood-onset disorders [10]. Tests should be designed to achieve high clinical validity (clinical sensitivity, negative and positive predictive values (PPV) and should have established clinical utility'. Current and/or future genome-wide approaches to ECS should also strive to minimise incidental findings [19] since the capacity of genetic services to provide follow-up 
counselling is limited (see, for example, the 2013 overview of clinical genetics staffing in selected European countries from a survey conducted by ESHG in 2013: [20]). Providers should also take into account individual differences in genetic risk and disease severity perception by the general population. Finally, increasing immigration of nonEuropean populations requires expansion of the disease coverage to those particularly occurring in large immigrant ethnic groups and may pose interpretational and counselling challenges both due to a different spectrum of diseaseassociated variants (often with unclear phenotypic impact, since there is a general lack of evidence in non-European populations because of the scarceness of respective studies) and to divergent cultural perceptions of examined individuals and/or of their families [16, 21, 22].

ECS may be of utility for infertile couples when donor gametes are used to allow the matching of the donor with the respective partner $[11,23]$. Couples who already have a child with a monogenic condition may also be interested in avoiding other genetic disorders, and consanguineous couples may also benefit from this approach. Consequently, increased use of ECS may lead to an increased use of PGD and thus less frequent requirement of prenatal diagnosis (PND), both leading to a decrease of elective termination of pregnancy (ETP) for severe genetic disease. Furthermore, antenatal ECS and genetic testing in different phases of life may become intertwined. While early offers of preconception ECS may target serious childhood conditions for which PGD or PND are an option to avoid the live birth of an affected child, ECS may also include treatable conditions (for example, phenylketonuria or medium-chain acyl-CoA dehydrogenase deficiency) to allow for treatment immediately after birth or even during pregnancy (for example, 21hydroxylase deficiency/congenital adrenal hyperplasia) [24, 25].

Finally, there is increasing evidence that combined lowgrade somatic and germline mosaicism eludes current detection techniques and that routine utilisation of blood leucocytes as a proxy for examination of germline variation is insufficient. Therefore, if economically and technically feasible it could be prudent to test in unclear cases genetic variation in the three major embryonic lineages in a given patient in order to estimate the degree of potential postzygotic mosaicism (i.e., from white blood cells reflecting mesoderm, urine sediment cells-endoderm and dry buccal swab cells or hair follicules-ectoderm). Nonetheless, even after such a complex genetic testing approach mosaicism cannot be completely excluded. In this regard low-grade undetected parental mosaicism may be responsible for erroneously assigned 'de novo status' for observed variation and could skew recurrence risk counselling [26]. Possible germline mosaicism should thus always be mentioned and couples should be informed about the empiric $<1 \%$ recurrence risk in simplex de novo variants [27].

Thus, ECS may provide a false sense of reassurance, and the lay and professional public should be duly educated in this regard [10].

The panel recommends that national professional organisations in the field of ART and medical/clinical genetics either adopt relevant international guidelines for ECS with modification if required, or develop their own guidelines on how to make ECS responsibly available for their respective populations. The panel also calls upon ECS providers to transparently declare the inherent limitations of the applied methodology.

\section{Advances in genetic testing and voiding of anonymity of gamete donors}

Historically, gamete donation has been predominantly anonymous. Moreover, many heterosexual parents choose not to disclose the donor origin to their children, regardless of whether the donation was anonymous or not [28, 29]. Most but not all European countries delegate the decision on whether to disclose to the parents [30].

Some registries, such as the Donor Sibling Registry [31], Donor-Conceived Register [32] and Family Tree DNA [33], allow donors, donor-conceived children and donor siblings to trace each other through genetic ancestry testing, thus possibly reversing the anonymity of the donor. When both parties have consented to find genetic relatives, there is little ethical and legal concern. However, within the context of DTC genetic testing, the discovery of relatives can be accidental and/or relatives may be traced without their prior knowledge or consent. In this regard, DTC genetic testing has already been used by several million people to determine their ancestry [30]. The results of these tests, which are usually provided commercially, enable the consumer to match relatives 'on-line'. This strategy has also already been broadly used by adoptees and foundlings [34]. Moreover, the current affordable costs of DTC genetic testing make it accessible to the majority of consumers in Europe and beyond.

With the growing use of DTC genetic testing, the anonymity of gamete donors can no longer be guaranteed $[30,35]$. It does not suffice for the donors to refrain from entering genetic data into the databank. If any of their relatives do, the donor's family can be 'collaterally' identified. Also children whose parents did not disclose that they were donor-conceived may inadvertently find out about their donor origin. DTC genetic testing may provide interesting information regarding an individual's ancestry (although even in this instance there is a potential for serious misuse of such information [36]) and sometimes even 
useful information on genetic predispositions. Furthermore, donor-conceived children may also find their half-siblings, the donor himself/herself or other relatives through ancestry testing [37, 38].

Consequently, anonymous gamete donors should be informed that even though the fertility centre or donor agency will strive to protect their identity, their anonymity cannot be absolutely guaranteed. They should be made aware of the fact that even if they do not submit their DNA to one of the donor registries, they themselves or one of their relatives could be identified. Also, the donor's own (future) biological offspring may find half-siblings through these registries. Those donating or conceiving with donated gametes should keep this possibility in mind when deciding whether or not to disclose their donor status/donor conception to their relatives. Another emerging issue is related to the fact that identity disclosure reopens substantiated analyses and legal discussions on numerical limits in donor conception regimes in terms of their potential population genetic impact [39].

The panel recommends that patients undergoing ART treatment with gamete donation should be informed that their children may eventually discover their donor by genetic testing. Furthermore, laboratories offering DTC genetic testing should transparently inform their customers about the potential impact of their services on the possible discovery of non-paternity or unknown family relationships. ART centres that are using anonymous gamete donors need to provide clear information that donors may eventually be traced.

\section{Advances in the genetics of fertility disorders}

The fields of male (MI) and female (FI) infertility have witnessed substantial research advances on the underlying genetic causes of infertility. However, it needs to be noted that $\mathrm{MI} / \mathrm{FI}$ are of complex multifactorial origin and have a very broad spectrum of clinical manifestations. Moreover, the diagnosis of 'infertility' is generally defined in clinical terms only, with little a priori patient stratification involved in scientific studies. Much of the stated research progress is mainly due to the utilisation of MPS and other 'omics' technologies, including state-of-the-art bioinformatics approaches. Nonetheless, despite such advances, current treatment options in MI/FI have not made a substantial progress $[40,41]$.

\section{Male infertility}

The algorithm of genetic testing in MI has not changed. Karyotyping (mainly aimed at examination of gonosomal aberrations, which are the major cause of MI) is followed by testing of disease-associated variants in the CFTR gene and/ or Y chromosome microdeletions. However, in $\sim 40 \%$ of all cases of MI the underlying genetic pathogenesis is unknown, 'idiopathic MI' [42]. Genetics might play a role but there still needs to be progress in the understanding of the roles of environmental factors, for example, obesity or endocrine disruptors [43], smoking and air pollution [40] and epigenetic mechanisms (see further). Another factor which is important to take into account in Western populations is the increasing paternal age and the concurrent increase of de novo germline disease-associated variants [44].

Recently, a 9-year prospective study from a single centre, comprising 1737 cases, has identified major causes of MI in $40 \%$ of all patients with regards to 'reduced total spermatozoa counts' [45]. Additional progress was brought by proteomics and expression profiling analyses [46], including the study of relevant animal models (for example, Mouse Genome Informatics) [47] and of the reproductive tract microbiome [48]. However, application of research outcomes into routine clinical practice has been hampered by unclear definitions of MI cohorts under study, including unclear specification of 'idiopathic MI' (i.e., what exclusion criteria were applied, what exclusion tests were utilised?), which precludes replication or evidence-based meta-analyses [49]. Another confounding factor is related to the fact that many studies use different standards for sperm analyses and do not always adhere to the standardised World Health Organisation criteria [49].

The association of SNV variation [50], drawn from genome-wide association studies (GWAS) in MI, is often based on small cohorts [42]. Nonetheless, there has been marked progress in the identification of disease genes and disease-associated variants in 'non-syndromic' MI. Some of the more prominent instances include teratozoospermia in its rare forms characterised by globozoospermia with disease-associated variation detected in DPY19L2 [51]; SPATA16 [52], macrozoospermia in AURKC [53], alterations of sperm flagella in TUN-STBG1 (Viville et al. 2017; personal communication) and asthenozoospermia in DNAH1 [54], CATSPER1, GALNTL5 [55]. In the case of spermatogenic failure characterised by azoospermia and/or oligozoospermia there has also been progress in terms of identification of disease genes comprising, for example, NROB1, NR5A1, TEX11, TEX15 [56] and MAGEB4, NANOS1, NR5A1, SOHLH1, SYCE1, TAF4B, WT1 and ZMYND15 (in alphabetical order) (see Table 1 for gene names). Interestingly, TEX11 is an X-linked gene with both SNV and CNV hemizygous disease-associated variants, causing female-transmitted male meiotic arrest [57]. Although there is no predominant disease-associated variation observed thus far, from the clinical point of view identification of such variation associated with 


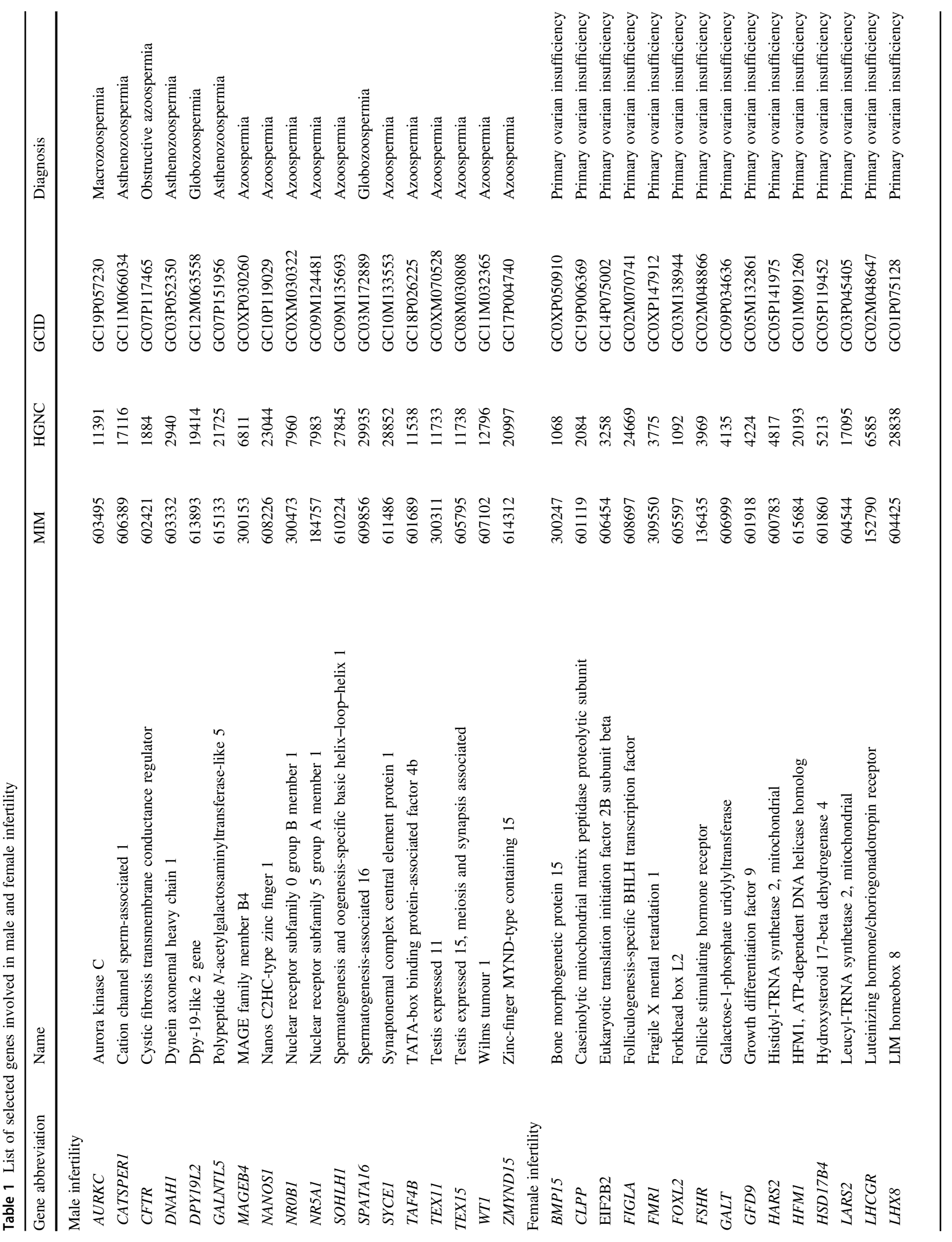




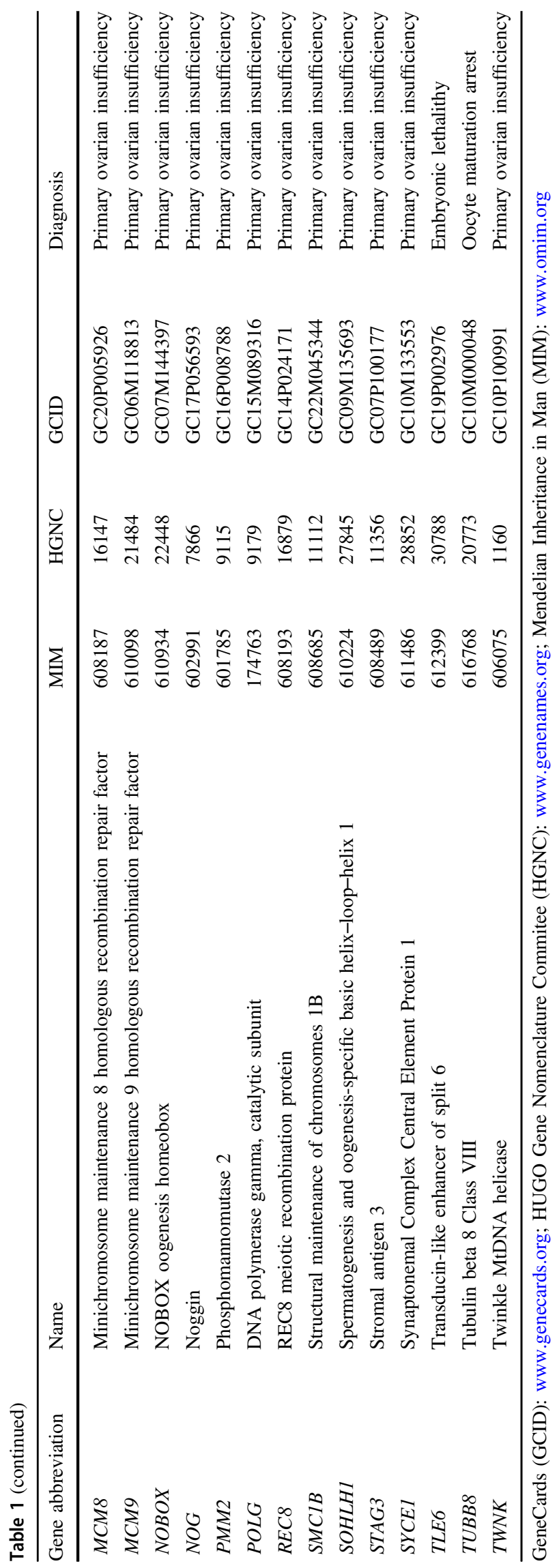

spermatogenic failure could indicate the utility of sperm cryopreservation at an appropriate age, to preserve fertility in individuals involved. Novel targeted biomarker assays are under development [40], which could improve genetic counselling and patient stratification for targeted ART treatment.

Awareness of rare genetic syndromes is also relevant in unexplained MI. Although such syndromes are often detected by a medical and family history, typical dysmorphic features, associated disabilities and medical examination, i.e., prior to the diagnosis of MI itself, there could be mild forms of these diseases presenting in adulthood as MI, due to improved standard medical and social care. These clinical entities, for example, comprise hypogonadotrophic hypogonadism (Kallmann syndrome-MIM: 308700), where MPS led to the identification of additional candidate genes [58]. Research progress has been made in the case of Klinefelter syndrome by application of testis transcriptomic analysis [59] MI is also commonly associated with rare syndromes with maldescended testes where most of the progress in research is again due to the application of MPS and bioinformatics: Noonan-MIM:163950 [60], Cleidocranial dysplasia-MIM:119600 [61], BloomMIM:210900 [62] and Silver-Russel syndromesMIM:180860 [63]. Likewise, primary ciliary dyskinesia (MIM: 244400) and myotonic dystrophy 1 (MIM: 160900), which are associated in their milder forms with MI, have been subjected to similar research strategies [64, 65].

The panel recommends that standardised clinical terminology and inclusion/exclusion criteria for MI should be used to allow replication studies and evidenced-based meta-analyses to move the field forward. Due to rapid progress in research, selected gene panels may soon become a useful tool allowing identification of additional causes of MI, and thus improve genetic- and reproductive counselling, facilitate patient stratification and therefore enable more precise ART approaches.

\section{Female infertility}

In the same way as in MI, research on the underlying genetic causes of FI is quickly advancing. Nonetheless, relatively little is still known about the genetic background of most cases of FI or female subfertility (FSF), and even less is translated into novel clinical practice. Evidently, FI is of complex multifactorial origin as reflected by the clinical and genetic heterogeneity of the cohorts under study, which then hinders replicability of previously performed analyses. Presumably hundreds of genes have to interact in a precise manner during sex determination, gametogenesis, complex hormone actions/interactions and embryo implantation and 
its early development, in order to create a healthy offspring. Thus, disorders related to FI/FSF are expected to be highly polygenic [66]. Considering that in mice more than 500 genes have already been associated with FI (MGI, see above) many more disease genes are waiting to be identified in humans in the coming years. Non-coding RNA's and epigenetic modifications have also been implicated in the control of ovarian function and thus their disturbances are likely to be associated with FI [67].

Chromosomal aberrations remain a major known cause of premature ovarian insufficiency (POI) and recurrent miscarriages, thus decreasing the chance of successful pregnancy $[68,69]$. A sizeable proportion of disorders of sexual development are also caused by gonosomal aberrations, and for other aetiologies, such as hypothalamic-pituitary-gonadal deficiencies, many additional disease-causing genes have already been identified [70].

There has been some progress in understanding of the role of genetic disease-causing genes in common multifactorial disorders such as polycystic ovary syndrome (PCOS) and endometriosis, each affecting around 10\% of women with FI/FSF. In PCOS, better patient stratification and functional genomics could provide novel research avenues [71, 72], while in endometriosis [73] abnormal epigenetic mechanisms in stromal cells may play a pathogenic role.

Progress has also been achieved in the identification of monogenic causes of FI/FSF, in particular for 'non-syndromic' POI for which multiple X-linked and autosomal genes have been identified as recently reviewed [74]. POI is highly clinically heterogeneous and is associated either with ovarian dysgenesis reflected by primary amenorrhoea or with secondary amenorrhoea. However, the majority of POI cases are 'idiopathic'. Additional disease-causing genes have been identified by candidate gene approaches, GWAS and/ or whole-exome analyses utilising MPS. However, diseaseassociated variants in these genes were reported in a rather small number of cases, some being confined to specific populations [66, 67, 75]. Interestingly, recent studies revealed a complex genetic architecture of POI [76]. The authors screened both known and potential candidate genes in a clinically well characterised cohort of patients. Diseaseassociated variants were found, for example, in $B M P 15$, FIGLA, FOXL2, GALT, GDF9, LHX8, NOBOX, REC8, $S M C 1 \beta$ and $S O H L H 1$ (in alphabetical order), which fall into transcription factor TGF- $\beta$ ligand, enzyme and 'meiosis' functional categories [53]. In the latter category, other authors have reported disease-associated variants in STAG3 [77], SYCE1 [78], HFM1 [79], MCM8 and MCM9 [80] (Table 1 for gene names). From the clinical point of view, variation linked to POI may also predict the risk of a premature menopause in affected families $[67,81]$.
The list of disease-causing genes related to 'syndromic' POI, where its pathogenesis is related to other clinical entities, was reviewed elsewhere [75]. In many instances, these multi-system syndromes rather than FI itself lead to the clinical diagnosis and referral for genetic testing, often in the pre-reproductive age. Disease-associated variants in the FOXL2 gene provide an example. Altered function of this gene causes the blepharophimosis/ptosis/epicanthus inversus syndrome (BPES; MIM: 110100) with or without POI. Progressive external ophthalmoplegia (MIM: 157640) together with other symptoms, including POI, is caused by disease-associated variants in $P O L G$ thereby implicating mitochondria-related pathology [82]. Disease-associated variants in GALT (MIM: 230400 for galactosaemia), PMM2 (MIM: 212065 for congenital disorders of glycosylation type Ia), CLPP (MIM: 614921 for congenital disorders of glycosylation type It), NOG (MIM: 185800 and 186500 for symphalangism 1a and multiple synostoses syndrome 1, respectively), EIF2B2 (MIM: 603896 for leukoencephaly with vanishing white matter syndrome) and HARS2 (MIM: 157400 for progressive external ophtamoplegia with mitochondrial DNA (mtDNA) deletions) have also been secondarily implicated in POI (see above) (see Table 1 for gene names). Likewise, disease-associated variants in several different disease-causing genes (CLPP, HARS2, HSD17B4, LARS2 and TWNK; in alphabetical order (see Table 1 for gene names) are implicated in the development of the Perrault syndrome (MIM: 233400), which associates sensorineural hearing loss and ovarian dysfunction [83]. Finally, CGG expansions in the 'premutation range' in the FMRl gene remain a well-established cause of isolated POI, more frequent in families with Fragile $\mathrm{X}$ syndrome (MIM: 300624), than in sporadic cases of POI.

Recently, dominant negative disease-associated variants in the TUBB8 gene, causing defects in spindle assembly and leading to oocyte maturation arrest, have been described in several families. This autosomal disorder was either maletransmitted or de novo and its phenotype was femalespecific [84]. Disease-associated variants in TLE6 were linked to preimplantation embryonic lethality [85]. Although the existence of the genuine empty follicle syndrome is still a matter of debate, disease-associated variants in the $\mathrm{LH} / \mathrm{CG}$ receptor gene (LHCGR) have been reported in this disorder [86].

There have also been advances in pharmacogenomics research focusing on the identification of genetic variation related to the individual response to controlled ovarian hyperstimulation $(\mathrm{COH})$. While a number of candidate genes are known, only FSH receptor $(F S H R)$ variation (the p.Asn680Ser 'polymorphism') has clinical utility due to its defined predictive value [87], and this variation was also linked to some instances of POI [88]. 
The panel concludes that the increasing knowledge of the genetic background, together with rapid technological developments, could foster improved diagnostics in FI. This means that in addition to the current routine testing of patients with POI for chromosomal aberrations and FMRI pre-mutations, selected gene panels may soon become a useful tool allowing identification of additional causes of FI, and thus improve genetic and reproductive counselling and patient stratification. The same is true for infertile women producing no or only non-viable oocytes or those suffering from premature menopause. Eventually, oocyte donation could be offered in a more personalised manner in FI.

\section{Advances in PGT}

PGT is defined as the multidisciplinary clinical application of genetic and ART technologies aimed at the examination of a limited number of cells of an embryo in its preimplantation phase of development in vitro, i.e., within the context of IVF. PGT is a complex sequential laboratory procedure, which requires multidisciplinary collaboration of ART specialists with laboratory geneticists experienced in the analysis of minimal numbers of cells.

Currently, the arbitrary distinction between the two major PGT modalities, comprising PGD and PGS, is gradually vanishing as genome-wide SNV and CNV variation genetic laboratory testing is being carried out simultaneously from the technical point of view. This is also reflected by the proposed change of nomenclature for these laboratory procedures within the 'International glossary on infertility and fertility care', which is currently in preparation by the International Committee for Monitoring Assisted Reproductive Technology [89]. There, PGT would become the 'root procedural term' to which chromosomal aneuploidy screening/testing (PGT-A) and PGT monogenic disease diagnosis (PGT-M) or any other genetic testing modality could be annexed.

PGT-M is aimed at diagnosing a specific 'Mendelian' genetic disorder in the embryo for which the prospective parents are at increased risk [90]. PGT-M has an advantage over conventional PND as it precludes the need to consider ETP in an affected ongoing pregnancy.

PGT-A (also known in the literature as PGS, 'PGD for aneuploidy screening/testing/- PGD-AS' or 'PGD for aneuploidy - PGD-A') is aimed at the detection of chromosomal aneuploidy (one or more of the 23 human chromosomes) in order to select (i.e., 'screen') embryos without diseaseassociated chromosomal aberrations. These embryos are expected to have the highest chance of proceeding to a healthy live birth. PGT-A is principally carried out to improve IVF efficiency [91]. The beneficial effect of PGTA utilising 'comprehensive chromosome screening' technology on clinical and sustained implantation rates, in particular in patients with normal ovarian reserve, has been documented in a meta-analysis [92]. However, as the studies included in the aforementioned paper only refer to good prognosis patients, more data are needed to confirm the validity of PGT-A for improving the clinical outcome of PGT-A in other patient categories and various stages of embryo biopsy [7]. It is important to note that since 'IVF success' has been defined by different authors in many ways, it is almost impossible to compare the outcomes of various studies within evidence-based meta-analysis [91]. Better patient stratification prior to PGT-A would help to assess which testing strategy is optimal for specific patient populations. Therefore, currently the beneficial effects of PGT-A do not have a sufficient level of evidence, as the results of standardised RCTs have not been published [7]. Since PGT-A is costly, 'positive' RCT outcomes also commonly represent a prerequisite for PGT-A reimbursement within most European health-care systems.

Since improved vitrification methods are currently being introduced [93] and a specific RCT has been carried out [94], selection of fresh embryos for transfer by PGT is increasingly being replaced by frozen embryo transfer. This approach allows for more time to perform high-quality PGT and aggregate more 'diagnostic cases' for simultaneous examination, which also decreases costs. Essentially, the increased utilisation of evidence-based PGT is intertwined with advances in embryo vitrification and reliant on highquality expertise in embryo micromanipulation [91], including properly established indicators [95].

Whole-genome haplotyping approaches, for example, karyomapping [94-98], as well as MPS-based whole-genome 'deep sequencing' allows for concurrent haplotyping, SNV and CNV examination, hence enabling aneuploidy assessment when specific PGT and informatics approaches are applied [99]. Haplotyping enables reliable PGT-M for virtually any inherited disease-associated variants (even without the necessity of a prior work up identifying the respective variants within a given family), while genomewide low-coverage MPS allows PGT-A, including diagnosis of partial chromosomal aneuploidies down to as little as $1.8 \mathrm{Mbp}$ in size [98-102]. Whereas most PGT-M testing methods to date had focused on analysing a single locus or a localised region of the genome, novel technical approaches may provide broader examination of an embryo's genomic variation. As a consequence, not only the genetic variants of interest, but also genomic variation unrelated to the original referral and request of the couple, may be detected. This approach opens novel ethical issues to be explored [103, 104] and subsequently professional guidelines ought to be developed. 
PGT, like all forms of clinical genetic testing, requires strict quality assurance and assessment. Regular participation in external quality assessment should be considered as essential and is indeed obligatory for genetic tests in some countries. PGT-specific schemes are readily available for both monogenic and aneuploidy testing in Europe, and beyond. Laboratory accreditation according to ISO15189 is still considered the most effective route to quality assurance [105] and its uptake is increasing in Europe, and beyond. It needs to be noted that technique-specific guidelines, such as those for diagnostic MPS, are equally relevant and important for PGT and should be observed [106, 107].

Likewise, the 'Standards and guidelines for the interpretation of sequence variants: a joint consensus recommendation of the American College of Medical Genetics and Genomics and the Association for Molecular Pathology' should be observed [108]. Moreover, Human Genome Variation Society recommendations on sequence variant nomenclature and proper assignment of 'disease association' in detected variants (hence reserving the prefix 'pathogenic' only to a clear set of diagnostic situations denoting that a given variant 'causes disease when in a specific context') [109], including relevant recommendations for the reporting of diagnostic tests, ought to be followed in PGT [110].

Another issue related to the clinical implementation of PGT-A is due to the fact that embryo mosaicism challenges provision of categorical (or 'conclusive') results. Although trophectoderm (TE; 'day 5' or 'day 6') biopsy allows for obtaining 'aggregate' template DNA from multiple embryonic cells, rather than one or two cells within a blastomere ('day 3') biopsy, it remains merely a general biopsy technique with its inherent limitations regarding the representativeness of the sample drawn in terms of the tissue/organ under study. These limitations are similar to those currently discussed in the domain of cancer, where accurate diagnosis and/or replicable research progress also to a large extent depend on the experience of the biopsy operator and exact position of the biopsy within the tissue of interest [111]. Therefore, the sample of cells obtained by embryo biopsy (at any given developmental stage) might not be representative of the entire embryo, as high rates of mosaicism have been also reported at the blastocyst stage [112]. In conclusion, while MPS improves analytical sensitivity and thus detection of mosaicism in a given embryo biopsy, it does not remedy the limitation that only the cells present in the biopsy are being analysed [113].

There already are reports on successful pregnancy outcomes following the replacement of selected mosaic aneuploidy blastocysts $[114,115]$. This observation, potentially changing the current paradigm of PGT-A, calls for followup multicentric studies to this initial observation and to duly prioritise embryos for transfer in terms of quantitative and qualitative parameters of embryo chromosomal mosaicism.
The chance of a healthy live birth will vary depending both on the rate of mosaicism and on the type of aneuploidy (which chromosome, monosomy vs. trisomy, are involved). The current challenge in this field is thus to define 'cut-off' levels, allowing to classify embryos as transferrable as first priority (i.e., no mosaicism detected), transferrable as second priority (i.e., moderate level of mosaicism with exclusion of those chromosomes potentially related to viable pathological conditions) and non-transferrable (i.e., excessive level of mosaicism or mosaics including chromosomes potentially related to viable pathological conditions [116]. Therefore, PGT-A could be considered primarily as a 'ranking tool' (i.e., a 'quantitative selection strategy'), rather than a 'screening tool' (i.e., 'qualitative selection strategy'), in order to discern euploid embryos from aneuploid ones [117].

This important observation leads to further questions about who should decide on the ranking or exclusion of embryos for transfer, and about what information is provided by the genetic laboratory to the ART clinician and IVF laboratory, and the prospective parents [103]. Comprehensive reproductive and genetic counselling with the latter is needed in order to ensure an adequate understanding by couples of the possibilities and limitations of the current genomics and ART approaches related to PGTA. Infertile couples also need to be made transparently aware of the fact that PGT-A alone cannot increase the live birth rate per cycle initiated, since it represents a ranking mechanism, not a therapy per se [7]. However, secondary outcome measures, such as mitigation of embryo implantation failures, miscarriage rate and cost-effectiveness, may be positively affected by performing PGT-A in specific patient populations [91, 101, 118]. PGT-A also allows negative selection of embryos with viable trisomies in selected couples with limited reproductive prospects, for example, owing to parental age. As current evidence is limited, more research has to be carried out and data from multicentric RCTs need to be gathered by harmonised methodologies, thereby enabling the proposed 'PGS 2.0' concept [91, 119, 120, 121]. Utilisation of advanced MPSbased technologies allowing sensitive and specific laboratory testing procedures together with the appropriate standardisation of IVF success reporting in accordance with the proposed 'ICMART' glossary (see above) could foster replicability of RCTs in PGT-A.

Even in the absence of RCTs, PGT-A is currently practised in an increasing number of laboratories globally. As soon as there is proven laboratory technology, which can select clearly non-viable embryos based on their chromosome constitution, the application of PGT-A could be considered as a part of medical practice in high-risk cases (for example, with advanced maternal age). By avoiding inevitable failure of respective ART cycles by deselecting 
evidently non-viable chromosomally abnormal embryos, PGT-A may mitigate unnecessary suffering of patients, improve the overall efficiency of IVF in the couple involved and decrease unnecessary $\mathrm{COH}$-related costs.

There has been promising research progress in the utilisation of blastocoele fluid (BF) [122, 123] serving as an alternative source of template DNA for PGT carried out by MPS [124]. BF reflects the chromosome status of the embryo (i.e., of the inner cell mass; ICM), compared to the sampling of TE cells, which represent only the extraembryonal tissues. BF is sampled by aspiration with a fine needle (blastocentesis), prior to embryo vitrification (see above). It has been documented that the timing of blastocoele re-expansion in vitrified-warmed cycles represents a favourable predictive factor for positive clinical pregnancy outcome: the faster the re-expansion of the blastocoele, the higher the further developmental potential of the blastocyst [125]. Research in this area is ongoing but when technical difficulties are overcome and outcomes of PGT-A following blastocentesis could be independently validated, then BF may become the preferred source of DNA for PGT.

Finally, utilisation of extracellular embryonic 'matrices', for example, drawn from spent in vitro culture media (CM), represents another research avenue for sampling of template DNA (although likely fragmented) for 'non-invasive PGT'. However, there are concerns that $\mathrm{CM}$ are not produced under 'human DNA-free' conditions and/or there remains a possibility that residual DNA from maternal (for example, cumulus) cells could be present [126, 127].

The future of PGT is closely related to the development of novel genome-wide MPS strategies, but also reliant on advances in blastocyst vitrification, together with appropriate embryo micromanipulation expertise of a given IVF centre. The majority of relevant professional guidelines for genetic/genomic testing within the 'postnatal domain' are applicable to PGT, including rigorous adherence to quality assurance.

The panel calls for a balanced view on the current role PGT-A in ART in terms of the overall improvement of IVF efficiency. Currently, PGT-A represents a ranking mechanism, which has documented positive impact in selected patient populations regarding positive secondary outcome measures such as reduction of embryo implantation failures or miscarriage rates.

The panel also calls for a standardised description of IVF success reporting (for example, related to live birth rate) so that current and/or future RCTs related to application of novel PGT-A approaches could be replicated and thus stand up to the requirements of evidence-based medicine, hence in support of the 'PGS 2.0 concept'.

Whole-genome approaches to PGT-A offer the potential to prioritise embryo transfer not only on the basis of the absence of disease-associated (SNV/ $\mathrm{CNV}$ ) variants related to the primary genetic referral and request of the infertile couple, but also the overall genetic constitution of the embryo. However, guidelines on how to use this information in the genetics laboratory are lacking, as are relevant ethical considerations, and thus need to be addressed by professional societies in the near future. Hopefully, novel techniques related to utilisation of $\mathrm{BF}$ or spent $\mathrm{CM}$ could overcome invasive template DNA sampling of the early embryo for PGT.

\section{Non-invasive PND and prenatal screening}

Similarly to 'procedural' characterisation of PGT (see above), the term NIPT should be generally reserved for the description of genetic technologies utilising the analysis of cell-free 'foetal' DNA (cffDNA) circulating in the maternal plasma [128]. Nonetheless, due to the initial clinical application of NIPT for the detection of selected foetal chromosomal aneuploidies (i.e., for chromosomes 13, 18, $21, \mathrm{X}$ and $\mathrm{Y}$ ), this term historically coalesced with this primary screening purpose (see below).

The 'foetal fraction' comprises $\sim 10 \%$ of cffDNA in the first trimester of pregnancy, and derives from the placenta. NIPT is equivalent to the concept of 'liquid biopsy' of the placenta, with all its diagnostic limitations historically gathered from the utilisation of chorionic villus biopsy [129, 130] as a source of template DNA in PND. The circulating genetic material of foetal origin can be either used for noninvasive prenatal diagnosis (NIPD) of, for example, monogenic disorders [131, 132], and/or to 'screen' for foetal chromosomal aneuploidy by non-invasive prenatal testing (NIPT; alternative terminology: non-invasive prenatal screening-NIPS [133]. The term NIPS is more appropriate since this prenatal screening process may also involve pregnant women without a priori genetic indication for their testing, such as in population-based screening schemes.

Implementation of NIPS in PND clinical practice has received considerable attention from professional societies, which have developed relevant guidelines [133, 134, 135]. Additional reports duly assessed the global outlook and barriers to the implementation of NIPS within the context of PND [136, 137], including its role in 'post-PGD' [138] pregnancies. Relevant ethical issues have been reviewed in a joint ESHG/American Society of Human Genetics 
document [139] and recently by the Nuffield Council of Bioethics [140].

NIPS has been widely introduced in the context of prenatal screening for common chromosomal aneuploidies from as early as the 10th week of pregnancy [141]. Lowcoverage genome-wide MPS together with advanced (often proprietary) bioinformatic algorithms are often used to determine the number of DNA fragments from each targeted chromosome in order to determine the probability of foetal chromosomal aneuploidy. Other approaches assess copy number by microarray or SNV analyses [142, 102]. The main benefit as compared with traditional combined first trimester antenatal screening (cFTS) [143], which is based on maternal age, ultrasound assessment of foetal nuchal translucency (NT) and selected biochemical biomarkers in maternal blood, are higher detection rates and a much lower percentage of false-positive (FP) results $(\sim 0.1 \%$ in NIPS as compared cFTS where it could be up to $5 \%$ ). NIPS thus reduces the overall number of follow-up invasive PND procedures and potentially iatrogenic miscarriages [142-146]. Nonetheless, there is increasing evidence that NIPS and cFTS are complementary approaches within the process of complex provision of antenatal screening in lowand high-risk pregnancies. Each approach has its inherent strengths and limitations, as reviewed for cFTS [147] and for NIPS [104], that could be pragmatically complemented within a synergistic (for example, contingent) diagnostic strategy [148]. Due to the fact that to date NIPS is not reimbursed by most European health-care systems, compared to established cFTS regional- or nationwide schemes, such a contigent approach might be cost effective for most solidarity-based health-care systems. For example, the UK NHS Rapid protocol suggests NIPS in women with a defined cFTS-related risk range, and thus might assure equitable access to antenatal screening [131, 149].

There are several specific issues related to the implementation of NIPS within broad antenatal screening strategies [150]. The first issue to be taken into account is related to the fact that, unlike NIPD for monogenic disorders, NIPS is not a diagnostic test. Tested individuals need to be aware that accuracy of NIPS is affected by confined placental mosaicism or detection of unexpected maternal chromosomal abnormalities. Thus, NIPS carried out by wholegenome techniques is not only a 'liquid biopsy' of the placenta [102, 151], but also detects other circulating DNA material, for example, originating from circulating tumour cells [152, 153].

The second issue is related to discussions as to how NIPS optimally fits within a comprehensive prenatal screening policy, taking into account also its cost-effectiveness [154, 155], and optimisation of its diagnostic yield [156]. A 'contingent' procedure, offering NIPS for intermediate risk cases after cFTS, would be beneficial in terms of costs and mitigate maternal stress following an inconclusive cFTS result. However, both the high sensitivity of NIPS and shorter waiting time are valuable if NIPS is applied as a first-line test. In this regard, studies which assessed the clinical utility of NIPS offered through primary obstetrical care providers to a general population of pregnant women provided evidence that NIPS has a high uptake and that patients understand its basic concept and limitations. The authors concluded that NIPS could be integrated into routine antenatal screening practice in primary care. Moreover, the complementarity of prenatal ultrasound NT measurements within the context of NIPS was also discussed [157, 158].

The third issue is whether NIPS should be offered for other abnormalities beyond common chromosomal aneuploidies, including sex chromosome abnormalities and clinically significant microdeletions (for example, for the detection of the DiGeorge syndrome; MIM: 188400). However, the rarity, marked genetic and clinical heterogeneity of these conditions, and thus the resulting low PPV, may lead to an undesirable increase in invasive PND procedures to account for more FP results $[159,160]$. Such a scenario could undo much of the potential benefits of introducing NIPS, hence addition of other clinical entities into NIPS 'panels' needs to be carefully considered. Nonetheless, some current commercial NIPS assays do include sex chromosome abnormalities and microdeletions, some of which may even have a variable phenotype. In some cases these may be of maternal origin. It is unclear whether informing apparently healthy women about their mosaicism is of clinical utility. As testing for milder conditions may not lead to termination, the clinical utility will depend on whether the findings enable better treatment for the child. On the positive side, parental awareness could enable treatment of some conditions at birth rather than waiting for symptoms to occur to trigger postnatal testing. On the other hand, there are also concerns that benefits may be outweighed by stigmatisation after diagnosis of phenotypically mild sex chromosomal anomalies or microdeletions. More research is needed to clarify this balance [139]. Some NIPS tests may even offer new opportunities for reproductive health, PGT and pregnancy management [102]. In summary, currently improved technology seems to 'push' the development of such testing offers, rather than established clinical utility and/or relevant patient/client perspectives.

The fourth issue is related to the quality of information and counselling with regard to all relevant aspects comprising incidental findings [139]. There is a concern that women are insufficiently made aware of the fact that NIPS is not a diagnostic test and that eventual ETP should therefore not be based on its findings alone, especially in low-risk populations, in which the PPV is significantly lower than in a high-risk population. A 'positive' NIPS 
result should always be followed by an invasive PND for verification, as in all other prenatal screening approaches.

Among the first applications of NIPD for monogenic disorders was foetal sexing [161] in X-linked recessive disorders, where the identification of a female foetus avoids the need for invasive PND [162]. The first gene-specific NIPD were introduced for paternally inherited autosomal dominant (AD) and AR disorders, where parents carry distinguishable disease-associated variants compared to the foetus. For other recessive disorders, the challenge still is to reliably discern between genetic information deriving from the foetus and from the pregnant woman [131, 132]. NIPD could also be used as a follow-up (confirmatory) procedure to PGT-M, mainly as an alternative to PND, in couples who are reluctant to undergo invasive procedures (for example, due to repeated IVF failure or parental anxiety), which are associated with a risk of iatrogenically induced pregnancy loss [138].

In view of future scenarios of non-invasive whole-genome NIPS, there is a need for debate about the overall scope of antenatal screening, also taking account of the informational privacy interests of the future child $[163,164]$. The possibility of foetal therapy might also impact on the indications for NIPD/NIPS in the near future. Should intrauterine treatment become possible for an increasing number of genetic conditions, including, for example, Down syndrome [165], then the informed decision needs to take into account such 'dual goals' of antenatal screening, be it cFTS or NIPS, or their combination.

The panel recommends that future interdisciplinary discussions are carried out between respective professional societies, which are responsible for the implementation of non-invasive antenatal screening policies and their potential association with the development of appropriate antenatal therapies. Individuals undergoing NIPS testing should be made aware of the fact that its positive results need to be confirmed by invasive PND. Moreover, tested individuals should be made aware that NIPS using wholegenome approaches may detect 'incidental' findings, for example, circulating tumour DNA in the mother. Finally, technological advances foster broader clinical implementation of NIPD as a more acceptable alternative to standard PND associated with invasive sampling of foetal cells or tissues.

\section{Mitochondria: from diagnosis to treatment}

\section{Preventing transmission of mtDNA disease-associated variants}

It is now technically possible to accurately establish the mtDNA disease-associated variant load (henceforward in legacy terminology 'mutation load') in different types of samples, including embryo biopsies and amniotic fluid, and therefore select an embryo/foetus with a mutation load below the threshold considered as 'pathogenic' when performing PGT-M and PND. Therefore, PGT-M and PND may be used to lower the risk of a child affected by various mitochondrial disorders [166, 167]. However, this 'selective' approach suffers from several drawbacks. One important issue is that there remains uncertainty whether the mutation load found in the tested sample is consistently representative of the rest of the embryo/foetus. Also, the mutation load may change during embryonic/foetal development, and it is difficult to establish the cut-off value for selection because of the uncertainty in correlation between the mutation load and resulting clinical symptoms. Finally, from a clinical point of view, there may be questions on the efficiency of this approach, as there is no guarantee that a woman with a given heteroplasmic load in her somatic tissues produces oocytes with a sufficiently low mutation load for a successful PGT cycle [168].

To address this issue, mitochondrial replacement therapy (MRT) has been developed [169, 170]. It consists of the transplantation of pronuclei, meiotic spindle or polar bodies of the patient's oocytes to the cytoplasm of enucleated donor oocytes, which are presumed to contain 'healthy' mitochondria. Pronuclear transfer was first performed in the mouse [171], but the resulting offspring showed high levels of mitochondrial carryover [170]. A second approach is based on transplanting pronuclei shortly after completion of meiosis rather than shortly before the first mitotic division, which results in lower mtDNA carryover [167, 172].

The spindle transfer technique was pioneered in the Rhesus monkey, where it proved to be efficient and safe [173]. The feasibility of mtDNA replacement by spindle transfer has also been demonstrated in the human, although some of these oocytes displayed abnormal fertilisation [174, 175]. The first birth of a child after spindle transfer was reported in a mother who carried a mtDNA mutation causing Leigh syndrome (MIM 256000) that resulted in four pregnancy losses and two deceased children. Although the child born after spindle transfer had a mutation load of $5.7 \%$ and was doing well at the time of reporting, long-term follow-up is necessary [176]. The first clinical pronuclear transfer in human oocytes with the result of a healthy birth was carried out in China. It was initially reported at the annual American Society of Reproductive Medicine Annual Meeting in 2003, but published only 13 years later [177]. Polar body transfer has been successfully achieved in the mouse [170] and recently also in humans [178]. However, there are inherent technical difficulties as polar bodies experience a brief lifetime owing to apoptotic pressures that lead to DNA fragmentation and degradation [170]. Overall, given the experimental nature of all these approaches, PGT 
and/or PND should always be considered after MRT, as an extra 'safety net' testing procedure.

Ethical issues under discussion include the acceptability of modifying the human genome [179], the role of the mitochondrial donor as a contributor to the 'parental project' (i.e., concept of 'three parent families' in the lay press) and implications for offspring identity, the proportionality of developing MRT technology as based on a view of the importance of genetic parenthood, and finding a balance between taking appropriate precautions and hampering innovation [180, 181, 182, 183].

\section{Autologous germline mitochondrial transfer to enhance/ improve embryo development}

Mitochondrial supplementation methods were introduced about two decades ago with the aim of overcoming poor oocyte quality and repeated IVF failure [184]. Despite the promising success rates of these first experimental trials, further research was largely abandoned because of safety concerns, particularly after such procedures resulted in $45, \mathrm{X}$ pregnancies. Articles evidencing the existence of adult oogonial (oocyte-generating) stem cells in mice, and possibly in women [185], have re-opened the prospects of delivering a source of pristine and patient-matched germline mitochondria to boost egg health and embryonic developmental potential without the need for young donor eggs to obtain 'healthy cytoplasm' [186]. However, broader clinical experience with this procedure is limited and the existence and role of adult oogonial stem cells in the human is still a matter of professional debate $[115,187]$.

\section{mtDNA copy number as a marker of embryo viability}

The mtDNA quantity in TE and blastomere biopsies has been associated with advanced female age and chromosomal aneuploidy, and proposed to provide an independent measure of embryonic implantation potential [188, 189]. The quantity of mtDNA appears significantly higher in embryos from older women and in aneuploid embryos, independent of the patient age. Blastocysts that successfully implant contain lower mtDNA quantities than those failing to implant, with a mtDNA quantity threshold above which implantation was never observed. However, many embryos that failed to implant also had mtDNA amounts below the said threshold. A recent study was not able to confirm these results, and found no statistically significant differences in blastocysts grouped by chromosomal ploidy, maternal age or implantation potential after application of a mathematical correction factor [190].

Conversely, it has been demonstrated that mtDNA is being reduced in the preimplantation embryo prior to its subsequent increase during the blastocyst stage [191]. To allow proper extrapolations from TE biopsies, it would be necessary to study the correlation between mtDNA content in the TE and the ICM of the blastocyst. Finally, it may be of value to measure the mtDNA content in a day 3 embryo growing in vitro to improve identification of viable embryos with a high developmental potential [192].

The panel concluded that application of various mitochondria-related procedures in ART still lack a sufficient level of evidence, and that further basic and translational research is necessary in this regard. Furthermore, relevant ethical issues need to be taken into consideration prior to the applications of these technologies in clinical practice.

\section{Epigenetic inheritance-related issues in ART}

Even though multiple definitions can be found for epigenetic inheritance, the most accepted one is as follows 'any potentially stable and heritable change in gene expression that occurs without a change in DNA sequence' [193, 194]. Epigenetics involves controlling the structure of the chromatin and the switching between an open to a closed configuration, thereby affecting transcription. Different modifications take place, such as covalent modification of DNA by methylation and/or post-translational modifications of proteins associated with DNA, mainly the histones [195]. So far, most experimental studies in the field of epigenetic inheritance have been performed using mouse models [196]. This implies that application of their outcomes to humans needs to be further substantiated.

Major epigenetic changes responsible for erasure and renewed establishment of the human epigenome occur during gametogenesis and early embryo development. These complex molecular processes include postfertilisation reprogramming to generate a totipotent zygote and are followed by germline reprogramming to generate gametes [197]. These processes together with environmental influences on the formation of human epigenome, especially during early development, are well documented [198, 199]. Consequently, there is a possibility that some ART procedures may inadvertently alter the gamete- and/or embryonal epigenome and potentially generate adverse medical consequences in the offspring.

The epigenetic mechanisms in gametes remain more or less a 'black box' at present, especially regarding oogenesis. In mice it has been shown that sperm DNA can be methylated and hydroxymethylated, but the exact role of such methylation processes is unclear. It is believed that methylation could both have a global impact on DNA stabilisation and a specific purpose, i.e., to silence (imprint) specific genes. It has also been shown that some specific genomic loci will keep their histones during meiosis, 
instead of exchanging them for protamines, and that this molecular mechanism is correlated with hypomethylation. It is hypothesised that the genes escaping protamination are the ones that need to be expressed very early during embryonic development [200]. After fertilisation, paternal DNA is actively demethylated, but some loci remain methylated (mainly in the case of imprinted genes). Thus far, the role of sperm DNA methylation in future embryonic development is not well understood [201].

The level of DNA methylation in the oocyte is half of that in spermatozoa. DNA methylation in the oocyte does not play a role in the regulation of gene expression of the oocyte itself, but is important for embryonic development [202]. Interestingly, regions that are methylated in the oocyte are more likely to be also methylated in the embryo [203]. These complex processes might be regulated by incomplete demethylation during the post-fertilisation reprogramming of the maternal allele or another kind of memory mechanism and present a potential way of epigenetic intergenerational inheritance of environmentally induced (for example, by $\mathrm{COH}$ and/or $\mathrm{CM}$ ) alterations in DNA methylation patterns of the oocyte [106].

Another function of DNA methylation in the germline is to control the expression of transposable elements (TPE). These are ancestral traces of retroviruses, representing approximately one-half of the human genome. TPE are reactivated during primordial germ cell formation and early development, and are tightly controlled not to jump 'anywhere' in the genome. The pathway(s) controlling the expression and transposition of TPE are not fully understood, thus far. However, in the mouse, potentially pathogenic alterations of proteins involved in their control can cause MI, mainly by a meiotic blockage at the pachytene stage [204, 205]. Recently, there is also growing evidence on the implication of TPE in various human diseases [206].

Animal studies have shown that ART procedures may be associated with multiple alterations in gene expression and DNA methylation, mainly of imprinted genes [207]. However, the potential relationship with phenotypic outcomes (if any) remains largely unknown. Also in human studies, epigenetic alterations associated with ART have been reported in embryos and placental tissue or umbilical cord blood [208]. However, these alternations have not yet been unambiguously associated with any clinically relevant outcomes, thus far. Future studies should focus on the normal epigenetic regulation in human gametes and embryos, the natural inter-individual variation in, for example, DNA methylation, the consequences of slight alterations in DNA methylation and phenotypical (long-term) consequences of epimutations [209].

Recently it was suggested that there is inter-individual variation in susceptibility to environmentally mediated epigenetic alterations in humans [210]. Furthermore, the environmentally induced epimutations occur possibly on a stochastic basis [211] making 'one-to-one' associations between an environmental clue and epigenetic alterations at a specific gene or set of genes less informative. This observation might also explain inconsistencies found between various studies. ART-induced epigenetic alterations, if they exist, might thus occur at random places in the genome, in only a subset of vulnerable subjects, probably leading to a wide range of adverse phenotypic consequences, which would complicate research on the potential epigenetic effects of ART [211]. Finally, it needs to be noted that these follow-up studies are also hampered by common parental unwillingness to disclose previous IVF treatments, including data security concerns regarding relevant patient registries.

The panel concluded that more research is needed on the potential impact of specific ART procedures on the epigenome and its consequences for the offspring, including possible epigenetic inheritance pathways. In addition, standardisation of follow-up methodologies and post-IVF patient registries could overcome complex biological issues and foster replicability of initial observations of adverse epigenetic inheritancerelated phenomena in children/adults conceived by IVF. Furthermore, relevant social and ethical issues related to this issue need to be explored.

\section{Germline genome editing}

Genome editing using tools allowing for exact modification, such as zinc-finger nucleases and TALENs (transcription activator-like effector nucleases), have been available for many years and have been widely used in research [212]. However, with the recent introduction of the CRISPR/Cas9 (clustered regularly interspaced short palindromic repeats/ Cas9 nuclease) system, genome editing has become much simpler, cheaper and more efficient, opening the road to somatic gene therapy and eventually also GGE [213].

GGE can be performed in different germ cell types, such as spermatogonial stem cells, in vitro matured oocytes, stem cell-derived gametes differentiated in vitro from pluripotent stem cell lines obtained after somatic cell nuclear transfer or induced pluripotent stem cells, and even in the early embryo [214, 215].

GGE at the embryo level has important technical drawbacks, such as incomplete editing leading to mosaic embryos and off-target effects (induced disease-associated variants at sites other than the intended on-target site) that need to be solved before considering possible clinical applications of the technique. As newer, more accurate, efficient, and therefore safer GGE systems are being developed, it is to be expected that these technical 
limitations could be overcome [216] as was recently documented in the case of hypertrophic cardiomyopathy [217].

Nevertheless, the number of clinical indications that could be envisaged for GGE remediation is limited, thus far, since PGT-M offers an alternative for couples at risk for a genetic disease in their offspring. The potential use of GGE could be envisioned in very high-risk couples, for example, if one partner is homozygous for an $\mathrm{AD}$ disease, or when both partners suffer from the same AR disorder. Less 'stringent' indications could be in cases where the number of embryos expected to be obtained after PGT-M is small, for example, in case of advanced maternal age, or couples at high risk for transmitting more than one genetic disease, or when HLA-matching embryos considered for curing a sibling affected by a severe monogenic disease. Other medical fields also started to discuss the potential implications of GGE [218]. Recently, the American Society of Human Genetics published their position statement on human GGE [219] and ESHG and ESHRE are jointly developing recommendations specific to this topic ('Responsible innovation in human germ-line genome editing'; de Wert et al, 2017, personal communication). Furthermore, there is an ongoing debate on the ethical (i.e., the 'slippery slope' argument) and social implications of GGE, and eventually current restrictions on GGE may require a renewed debate [220-223]. Finally, a transparent and broad collaboration is necessary in order to move the field of GGE responsibly forward [224, 225].

The panel concluded that although research in the field of GGE is rapidly developing, its potential medical applications within the context of ART and genetic medicine require further basic and translational research. Consensus guidelines need to be developed by respective professional societies, which will take into account any potentially adverse individual-, population genetic-, ethical- and societal implications of this novel medical technology.

\section{Conclusion}

The intersection of ART and genomics is a fast growing scientific field, both from the basic and translational research points of view. A selected portfolio of emerging topics was included in the agenda for the third panel meeting, mainly covering issues, which have the highest potential of entering, or that are already part of, current clinical practice. As molecular genetic techniques are improved, complete characterisation of the entire human genome variation of an embryo might become a reality. Together with the emergence of therapeutic possibilities comprising, for example, mitochondrial transfer and GGE, professional and ethical discussions around these developments need to be undertaken and international recommendations drawn up in order to determine how such novel technologies ought to be implemented in ART practice in a responsible and evidence-based manner, and accordingly regulated. The panel looks forward to the fourth meeting to discuss these ongoing developments at a European level in the near future.

\section{What does this mean for patients?}

This paper is the report of a meeting of experts from around Europe to assess how the latest developments in genetics might impact on assisted reproduction.

Their discussion included testing for genetic diseases for people wanting to get pregnant and the growth of commercial genetic testing, which may mean that anonymity for people who have donated eggs or sperm cannot be guaranteed. They also considered advances in identifying genetic factors in both male and female infertility and in genetic testing or screening of embryos. They discussed early pregnancy screening and techniques involving mitochondria as well as the impact of IVF on the way genes might work and new techniques for editing, or altering, genes.

They concluded that developments in genetics are increasingly relevant in the fertility field as some new techniques are already being used in clinics. They called for international recommendations to consider how new technologies should be introduced into the field of assisted reproduction.

Acknowledgements We would like to acknowledge the editorial support of Anuska Linares Baraza from the Centre for Regenerative Medicine in Barcelona and Inga Prokopenko MSc, $\mathrm{PhD}$ from the Department of Genomics of Common Disease, School of Public Health, Imperial College London for her helpful comments on the final manuscript.

Author contributions J.C.H. and M.M. conceived the idea, designed the paper, edited individual authors' contributions and the final manuscript. All authors wrote sections on their topic in the full manuscript. All authors edited and validated the final manuscript.

Funding Participation in the meeting from which this article arose was funded by European Society of Human Reproduction and Embryology and European Society of Human Genetics. M.M. was supported by IP00064203/6003, CZ.2.16/3.1.00/24022, CZ.02.1.01/0.0/0.0/16_013/ 0001634 and LM2015091 from the Czech Ministry of Health and Czech Ministry of Youth, Education and Sports.

\section{Compliance with ethical standards}

Conflict of interest Joris Vermeesch applied for patents ZL910050PCT/EP2011/060211-WO/2011/157846 'Methods for haplotyping 
single cells' and ZL913096-PCT/EP2014/068315-WO/2015/ 028576 'Haplotyping and copy number typing using polymorphic variant allelic frequencies' licensed to Agilent Technologies. Joyce Harper is Director of the Embryology and PGD Academy and Director of Global Women Connected. The remaining authors declare that they have no competing interests.

Open Access This article is licensed under a Creative Commons Attribution-NonCommercial-ShareAlike 4.0 International License, which permits any non-commercial use, sharing, adaptation, distribution and reproduction in any medium or format, as long as you give appropriate credit to the original author(s) and the source, provide a link to the Creative Commons license, and indicate if changes were made. If you remix, transform, or build upon this article or a part thereof, you must distribute your contributions under the same license as the original. The images or other third party material in this article are included in the article's Creative Commons license, unless indicated otherwise in a credit line to the material. If material is not included in the article's Creative Commons license and your intended use is not permitted by statutory regulation or exceeds the permitted use, you will need to obtain permission directly from the copyright holder. To view a copy of this license, visit http://creativecommons. org/licenses/by-nc-sa/4.0/.

\section{Appendix}

$\begin{array}{ll}\text { AD } & \text { autosomal dominant } \\ \text { AR } & \text { autosomal recessive } \\ \text { ART } & \text { assisted reproductive technology } \\ \text { CNV } & \text { copy number variants } \\ \text { CRISPR } & \text { Clustered Regularly Interspaced Short Palindromic } \\ & \text { Repeats } \\ \text { DTC } & \text { direct to consumer (genetic testing) } \\ \text { ECS } & \text { expanded carrier screening } \\ \text { ESHG } & \text { European Society of Human Genetics } \\ \text { ESHRE } & \text { European Society of Human Reproduction and } \\ & \text { Embryology } \\ \text { ETP } & \text { elective termination of pregnancy } \\ \text { FI } & \text { female infertility } \\ \text { GGE } & \text { germline genome editing } \\ \text { IVF } & \text { in vitro fertilisation } \\ \text { MI } & \text { male infertility } \\ \text { MIM } & \text { Mendelian inheritance in man (number) } \\ \text { MPS } & \text { massive parallel sequencing } \\ \text { mtDNA } & \text { mitochondrial DNA } \\ \text { NIPD } & \text { non-invasive prenatal diagnosis } \\ \text { NIPT } & \text { non invasive prenatal testing } \\ \text { NIPS } & \text { non invasive prenatal screening } \\ \text { PCOS } & \text { polycystic ovary syndrome } \\ \text { PGD } & \text { preimplantation genetic diagnosis } \\ \text { PGS } & \text { preimplantation genetic screening } \\ \text { PGT } & \text { preimplantation genetic testing } \\ \text { PGT-A } & \text { preimplantation genetic testing-aneuploidy } \\ \text { PGT-M } & \text { preimplantation genetic testing-Mendelian disorders } \\ \text { PND } & \text { prenatal diagnosis } \\ & \end{array}$

PPV positive predictive values

SNV single nucleotide variants

SV structural variants

WHO World Health Organisation

\section{References}

1. ESHG: European Society for Human Genetics. (2017).https:// www.eshg.org (Accessed 14 Sep 2017).

2. ESHRE: European Society for Human Reproduction and Embryology. (2017). https://www.eshre.eu (Accessed 14 Sep 2017).

3. Harper JC, Geraedts J, Borry P, et al. Current issues in medically assisted reproduction and genetics in Europe: research, clinical practice, ethics, legal issues and policyeuropean society of human genetics and european society of human reproduction and embryology. Eur J Hum Genet. 2013;21:S1-21.

4. Soini S, Ibarreta D, Anastasiadou V, et al. The interface between assisted reproductive technologies and genetics: technical, social, ethical and legal issues. Eur J Hum Genet. 2006;14:588-645.

5. Calhaz-Jorge C, de Geyter C, et al. European IVF-Monitoring Consortium (EIM) for the European Society of Human Reproduction and Embryology (ESHRE). Assisted reproductive technology in Europe, 2012: results generated from European registers by ESHRE. Hum Reprod. 2016; 31: 1638-52.

6. Brownstein CA, Beggs AH, Homer N, et al. An international effort towards developing standards for best practices in analysis, interpretation and reporting of clinical genome sequencing results in the CLARITY challenge. Genome Biol. 2014;15:R53.

7. Harper J, Jackson E, Sermon K, et al. Adjuncts in the IVF laboratory: where is the evidence for 'add-on' interventions? Hum Reprod. 2017;32:485-91.

8. Committee Opinion No. 690: Carrier screening in the age of genomic medicine American College of Obstetricians and Gynecologists. Obstet Gynecol 2017;129:e35- 40.

9. Edwards JG, Feldman G, Goldberg J, et al. Expanded carrier screening in reproductive medicine-points to consider. Obstet Gynecol. 2015;125:653-62.

10. Henneman L, Borry P, Chokoshvili D, et al. Responsible implementation of expanded carrier screening. Eur J Hum Genet 2016;24:e1-12.

11. Abulí A, Boada M, Rodríguez-Santiago B, et al. NGS-based assay for the identification of individuals carrying recessive genetic mutations in reproductive medicine. Hum Mutat. 2016;37:516-23.

12. Borry P, Henneman L, Lakeman P, ten Kate LP, Cornel MC, Howard HC. Preconceptional genetic carrier testing and the commercial offer directly-to-consumers. Hum Reprod. 2011;26:972-7.

13. Castellani C, Picci L, Tridello G, et al. Cystic fibrosis carrier screening effects on birth prevalence and newborn screening. Genet Med. 2016;18:145-51.

14. Janssens S, Chokoshvili D, Vears D, De Paepe A, Borry P. Attitudes of european geneticists regarding expanded carrier screening. J Obstet Gynecol neonatal Nurs. 2017;46:63-71.

15. De Wert G, Dondorp W, Pennings G, Shenfield F, Devroey P, Tarlatzis B, Barri P, Diedrich K. ESHRE Task Force on Ethics and Law. Intrafamilial medically assisted reproduction. Hum Reprod 2011;26(3):504-509.

16. Holtkamp KCA, Mathijssen IB, Lakeman P, et al. Factors for successful implementation of population-based expanded carrier 
screening: learning from existing initiatives. Eur J Public Health. 2017;27:372-7.

17. Acuna-Hidalgo R, Veltman JA, Hoischen A. New insights into the generation and role of de novo mutations in health and disease. Genome Biol. 2016;17:241.

18. Dubov T, Toledano-Alhadef H, Bokstein F, Constantini S, BenShachar S. The effect of parental age on the presence of de novo mutations - Lessons from neurofibromatosis type I. Mol Genet genomic Med. 2016;4:480-6.

19. Howard HC, Knoppers BM, Cornel MC, et al. Whole-genome sequencing in newborn screening? A statement on the continued importance of targeted approaches in newborn screening programmes. Eur J Hum Genet 2015;23:1593-600.

20. ESHG: Staffing of medical genetics centres across Europe. 201). https://www.eshg.org/index.php?id=111. (Accessed 14 Sep 2017).

21. Boeldt DL, Schork NJ, Topol EJ, Bloss CS. Influence of individual differences in disease perception on consumer response to direct-to-consumer genomic testing. Clin Genet. 2015;87:225-32.

22. El-Hazmi MAF. Ethics of genetic counseling - basic concepts and relevance to Islamic communities. Ann. Saudi Med. 2004;24:84-92.

23. Dondorp W, De Wert G, Pennings G, et al. ESHRE Task Force on Ethics and Law 21: genetic screening of gamete donors: ethical issues. Hum Reprod. 2014;29:1353-9.

24. Bachelot A, Grouthier V, Courtillot C, Dulon J, Touraine P. MANAGEMENT OF ENDOCRINE DISEASE: Congenital adrenal hyperplasia due to 21-hydroxylase deficiency: update on the management of adult patients and prenatal treatment. Eur $\mathbf{J}$ Endocrinol. 2017;176:R167-81.

25. Simpson JL, Rechitsky S. Preimplantation diagnosis and other modern methods for prenatal diagnosis. J Steroid Biochem Mol Biol. 2017;165:124-30.

26. Campbell IM, Shaw CA, Stankiewicz P, Lupski JR. Somatic mosaicism: implications for disease and transmission genetics. Trends Genet. 2015;31:382-92.

27. Campbell IM, Stewart JR, James RA, et al. Parent of origin, mosaicism, and recurrence risk: probabilistic modeling explains the broken symmetry of transmission genetics. Am J Hum Genet. 2014;95:345-59.

28. Blake L, Jadva V, Golombok S. Parent psychological adjustment, donor conception and disclosure: a follow-up over 10 years. Hum Reprod. 2014;29:2487-96.

29. Sälevaara M, Suikkari A-M, Söderström-Anttila V. Attitudes and disclosure decisions of Finnish parents with children conceived using donor sperm. Hum Reprod. 2013;28:2746-54.

30. Harper JC, Kennett D, Reisel D. The end of donor anonymity: how genetic testing is likely to drive anonymous gamete donation out of business. Hum Reprod. 2016;31:1135-40.

31. DSR: Donor Sibling Registry. 2017. www.donorsiblingregistry. com (Accessed 14 Sep 2017).

32. DCR: Donor Conceived Registry. 2017. www. donorconceiveregistry.org.uk (Accessed 14 Sep 2017).

33. FTDNA: Family Tree DNA. https://www.familytreedna.com (Accessed 14 Sep 2017).

34. Baptista NM, Christensen KD, Carere DA, Broadley SA, Roberts JS, Green RC. Adopting genetics: motivations and outcomes of personal genomic testing in adult adoptees. Genet Med. 2016;18:924-32.

35. Zadeh S. Disclosure of donor conception in the era of nonanonymity: safeguarding and promoting the interests of donorconceived individuals? Hum Reprod. 2016;31:2416-20.

36. Abbott A. Genome test slammed for assessing 'racial purity'. Nature. 2012;486:167.
37. Patrinos GP, Baker DJ, Al-Mulla F, Vasiliou V, Cooper DN. Genetic tests obtainable through pharmacies: the good, the bad, and the ugly. Hum Genomics. 2013;7:17.

38. Borry P, Rusu O, Dondorp W, De Wert G, Knoppers BM, Howard HC. Anonymity 2.0: direct-to-consumer genetic testing and donor conception. Fertil Steril. 2014;101:630-2.

39. Millbank J. Numerical limits in donor conception regimes: genetic links and 'extended family' in the era of identity disclosure. Med Law Rev. 2014;22:325-56.

40. Bieniek JM, Lo KC. Recent advances in understanding \& amp; managing male infertility. F1000Research. 2016;5:2756.

41. Hanson B, Johnstone E, Dorais J, Silver B, Peterson CM, Hotaling J. Female infertility, infertility-associated diagnoses, and comorbidities: a review. J Assist Reprod Genet. 2017;34:167-77.

42. Krausz C, Escamilla AR, Chianese C. Genetics of male infertility: from research to clinic. Reproduction. 2015;150:R159-74.

43. Ankolkar M, Balasinor NH. Endocrine control of epigenetic mechanisms in male reproduction. Horm Mol Biol Clin Investig. 2016;25:65-70.

44. Girard SL, Bourassa CV, Lemieux Perreault L-P, et al. Paternal age explains a major portion of de novo germline mutation rate variability in healthy individuals. PLoS One. 2016;11:e0164212.

45. Punab M, Poolamets O, Paju P, et al. Causes of male infertility: a 9-year prospective monocentre study on 1737 patients with reduced total sperm counts. Hum Reprod. 2017;32:18-31.

46. Carrell DT, Aston KI, Oliva R, Emery BR, De Jonge CJ. The 'omics' of human male infertility: integrating big data in a systems biology approach. Cell Tissue Res. 2016;363:295-12.

47. MGI: Mouse Genome Informatics. 2017. http://www.informa tics.jax.org/. (Accessed 20 Apr 2017).

48. Franasiak JM, Scott RT. Reproductive tract microbiome in assisted reproductive technologies. Fertil Steril. 2015;104:1364-71.

49. Hotaling J, Carrell DT. Clinical genetic testing for male factor infertility: current applications and future directions. Andrology. 2014;2:339-50.

50. Aston KI. Genetic susceptibility to male infertility: news from genome-wide association studies. Andrology. 2014;2:315-21.

51. Ghédir H, Ibala-Romdhane S, Okutman O, Viot G, Saad A, Viville S. Identification of a new DPY19L2 mutation and a better definition of DPY19L2 deletion breakpoints leading to globozoospermia. Mol Hum Reprod. 2016;22:35-45.

52. ElInati E, Fossard C, Okutman O, et al. A new mutation identified in SPATA16 in two globozoospermic patients. J Assist Reprod Genet. 2016;33:815-20.

53. Ben Khelifa M, Coutton C, Blum MGB, et al. Identification of a new recurrent aurora kinase $\mathrm{C}$ mutation in both European and African men with macrozoospermia. Hum Reprod. 2012;27:3337-46.

54. Amiri-Yekta A, Coutton C, Kherraf Z-E, et al. Whole-exome sequencing of familial cases of multiple morphological abnormalities of the sperm flagella (MMAF) reveals new DNAH1 mutations. Hum Reprod. 2016;31:2872-80.

55. Takasaki N, Tachibana K, Ogasawara S, et al. A heterozygous mutation of GALNTL5 affects male infertility with impairment of sperm motility. Proc Natl Acad Sci U S A. 2014;111:1120-5.

56. Okutman O, Muller J, Baert Y, et al. Exome sequencing reveals a nonsense mutation in TEX15 causing spermatogenic failure in a Turkish family. Hum Mol Genet. 2015;24:5581-8.

57. Yatsenko AN, Georgiadis AP, Röpke A, et al. X-Linked TEX11 mutations, meiotic arrest, and azoospermia in infertile men. $\mathrm{N}$ Engl J Med. 2015;372:2097-107.

58. Quaynor SD, Bosley ME, Duckworth CG, et al. Targeted next generation sequencing approach identifies eighteen new 
candidate genes in normosmic hypogonadotropic hypogonadism and kallmann syndrome. Mol Cell Endocrinol. 2016;437:86-96.

59. D'Aurora M, Ferlin A, Di Nicola M, et al. Deregulation of sertoli and leydig cells function in patients with Klinefelter syndrome as evidenced by testis transcriptome analysis. BMC Genomics. 2015; 16:156.

60. Pevec U, Rozman N, Gorsek B, Kunej T. RASopathies: presentation at the genome, interactome, and phenome levels. Mol Syndromol. 2016;7:72-9.

61. Guo Y-W, Chiu C-Y, Liu C-L, Jap T-S, Lin L-Y. Novel mutation of RUNX2 gene in a patient with cleidocranial dysplasia. Int J Clin Exp Pathol. 2015;8:1057-62.

62. Liu T, Huang J. DNA end resection: facts and mechanisms. Genomics Proteomics Bioinformatics. 2016;14:126-30.

63. Giabicani E, Netchine I, Brioude F. New clinical and molecular insights into silver-russell syndrome. Curr Opin Pediatr. 2016;28:529-35.

64. Marshall CR, Scherer SW, Zariwala MA, et al. Whole-exome sequencing and targeted copy number analysis in primary ciliary dyskinesia. G3 (Bethesda). 2015;5:1775-81.

65. Santoro M, Masciullo M, Silvestri G, Novelli G, Botta A. Myotonic dystrophy type 1: role of CCG, CTC and CGG interruptions within DMPK alleles in the pathogenesis and molecular diagnosis. Clin Genet. 2016. http://oi:10.1111/ cge. 12954 .

66. Laissue P. Aetiological coding sequence variants in nonsyndromic premature ovarian failure: From genetic linkage analysis to next generation sequencing. Mol Cell Endocrinol. 2015;411:243-57.

67. Pelosi E, Forabosco A, Schlessinger D. Genetics of the ovarian reserve. Front Genet. 2015;6:308.

68. Yatsenko SA, Rajkovic A. Chromosomal causes of infertility: the story continues. In: Sermon K, Viville S, editors. Textbook of Human Reproductive Genetics. Cambridge: Cambridge University Press; 2014. p. 97.

69. Tucker EJ, Grover SR, Bachelot A, Touraine P, Sinclair AH. Premature ovarian insufficiency: new perspectives on genetic cause and phenotypic spectrum. Endocr Rev. 2016;37:609-35.

70. Liebaers I, El Inati E, Lissens W, Viville S. Genes and infertility. In: Sermon K, Viville S, editors. Textbook of Human Reproductive Genetics. Cambridge: Cambridge University Press; 2014; p. 113.

71. McAllister JM, Legro RS, Modi BP, Strauss JF. Functional genomics of PCOS: from GWAS to molecular mechanisms. Trends Endocrinol Metab. 2015;26:118-24.

72. Pau CT, Mosbruger T, Saxena R, Welt CK. Phenotype and tissue expression as a function of genetic risk in polycystic ovary syndrome. PLoS One. 2017;12:e0168870.

73. Yotova I, Hsu E, Do C, et al. Epigenetic alterations affecting transcription factors and signaling pathways in stromal cells of endometriosis. PLoS One. 2017;12:e0170859.

74. Rossetti R, Ferrari I, Bonomi M, Persani L. Genetics of primary ovarian insufficiency. Clin Genet. 2017;91:183-98.

75. Qin Y, Jiao X, Simpson JL, Chen Z-J. Genetics of primary ovarian insufficiency: new developments and opportunities. Hum Reprod Update. 2015;21:787-808.

76. Bouilly J, Beau I, Barraud S, et al. Identification of multiple gene mutations accounts for a new genetic architecture of primary ovarian insufficiency. J Clin Endocrinol Metab. 2016;101:4541-50.

77. Caburet S, Arboleda VA, Llano E, et al. Mutant cohesin in premature ovarian failure. N Engl J Med. 2014;370:943-49.

78. de Vries L, Behar DM, Smirin-Yosef P, Lagovsky I, Tzur S, Basel-Vanagaite L. Exome sequencing reveals SYCE1 mutation associated with autosomal recessive primary ovarian insufficiency. J Clin Endocrinol Metab. 2014;99:E2129-32.
79. Wang J, Zhang W, Jiang H, Wu B-L. Primary ovarian insufficiency collaboration. mutations in HFM1 in recessive primary ovarian insufficiency. N Engl J Med. 2014;370:972-4.

80. Desai S, Wood-Trageser M, Matic J, et al. MCM8 and MCM9 nucleotide variants in women with primary ovarian insufficiency. J Clin Endocrinol Metab. 2017;102:576-82.

81. Laven J. Genetics of early and normal menopause. Semin Reprod Med. 2015;33:377-83.

82. Demain LAM, Conway GS, Newman WG. Genetics of mitochondrial dysfunction and infertility. Clin Genet. 2017;91:199-207.

83. Demain LAM, Urquhart JE, O'Sullivan J, et al. Expanding the genotypic spectrum of Perrault syndrome. Clin Genet 2017;91:302-12.

84. Feng R, Yan Z, Li B, et al. Mutations in TUBB8 cause a multiplicity of phenotypes in human oocytes and early embryos. J Med Genet. 2016;53:662-71.

85. Alazami AM, Awad SM, Coskun S, et al. TLE6 mutation causes the earliest known human embryonic lethality. Genome Biol. 2015;16:240.

86. Yuan P, He Z, Zheng L, et al. Genetic evidence of 'genuine' empty follicle syndrome: a novel effective mutation in the LHCGR gene and review of the literature. Hum Reprod. 2017;32:1-10.

87. Tang H, Yan Y, Wang T, Zhang T, Shi W, Fan R, Yao Y, Zhai S. Effect of follicle-stimulating hormone receptor Asn680Ser polymorphism on the outcomes of controlled ovarian hyperstimulation: an updated meta-analysis of 16 cohort studies. J Assist Reprod Genet. 2015;32(12):1801-10. https://doi.org/10. 1007/s10815-015-0600-5. Epub 2015 Oct 19.

88. Cordts EB, Santos MC, Bianco B, Barbosa CP, Christofolini DM. Are FSHR polymorphisms risk factors to premature ovarian insufficiency? Gynecol Endocrinol. 2015;31:663-6.

89. Zegers-Hochschild F, Adamson GD, Dyer S, Racowsky C, de Mouzon J, Sokol R, et al. The International Glossary on Infertility and Fertility Care, 2017. Fertil Steril 2017;108(3):393-406. https://doi.org/10.1016/j.fertnstert.2017.06.005. Epub 2017 Jul 29

90. Traeger-Synodinos J. Pre-implantation genetic diagnosis. Best Pract Res Clin Obstet Gynaecol. 2017;39:74-88.

91. Geraedts J, Sermon K. Preimplantation genetic screening 2.0: the theory. Mol Hum Reprod. 2016;22:839-44.

92. Dahdouh EM, Balayla J, García-Velasco JA. Comprehensive chromosome screening improves embryo selection: a metaanalysis. Fertil Steril. 2015;104:1503-12.

93. Vajta G, Rienzi L, Ubaldi FM. Open versus closed systems for vitrification of human oocytes and embryos. Reprod Biomed Online. 2015;30:325-33.

94. Coates A, Kung A, Mounts E, et al. Optimal euploid embryo transfer strategy, fresh versus frozen, after preimplantation genetic screening with next generation sequencing: a randomized controlled trial. Fertil Steril 2017;107:723-e3.

95. Wilkinson J, Roberts SA, Vail A. Developments in IVF warrant the adoption of new performance indicators for ART clinics, but do not justify the abandonment of patient-centred measures. Hum Reprod. 2017; 1-5.

96. Natesan SA, Handyside AH, Thornhill AR, et al. Live birth after PGD with confirmation by a comprehensive approach (karyomapping) for simultaneous detection of monogenic and chromosomal disorders. Reprod Biomed Online. 2014;29:600-5.

97. Natesan SA, Bladon AJ, Coskun S, et al. Genome-wide karyomapping accurately identifies the inheritance of single-gene defects in human preimplantation embryos in vitro. Genet Med. 2014;16:838-45.

98. Thornhill AR, Handyside AH, Ottolini C, et al. Karyomapping-a comprehensive means of simultaneous monogenic and 
cytogenetic PGD: comparison with standard approaches in real time for Marfan syndrome. J Assist Reprod Genet. 2015;32:347-56.

99. Zamani Esteki M, Dimitriadou E, Mateiu L, et al. Concurrent whole-genome haplotyping and copy-number profiling of single cells. Am J Hum Genet. 2015;96:894-912.

100. Zheng H, Jin H, Liu L, Liu J, Wang W-H. Application of nextgeneration sequencing for 24-chromosome aneuploidy screening of human preimplantation embryos. Mol Cytogenet. 2015;8:38.

101. Sermon K, Capalbo A, Cohen J, et al. The why, the how and the when of PGS 2.0: current practices and expert opinions of fertility specialists, molecular biologists, and embryologists. Mol Hum Reprod. 2016;22:845-57.

102. Vermeesch JR, Voet T, Devriendt K. Prenatal and preimplantation genetic diagnosis. Nat Rev Genet 2016;17:643-56.

103. Hens K, Dondorp W, Handyside AH, et al. Dynamics and ethics of comprehensive preimplantation genetic testing: a review of the challenges. Hum Reprod Update. 2013;19:366-75.

104. Van den Veyver IB. Recent advances in prenatal genetic screening and testing. F1000Research. 2016;5:2591.

105. Harper JC, SenGupta S, Vesela K, et al. Accreditation of the PGD laboratory. Hum Reprod. 2010;25:1051-65.

106. Marianowski P, Dąbrowski FA, Zyguła A, Wielgoś M, Szymusik I. Do we pay enough attention to culture conditions in context of perinatal outcome after in vitro fertilization? up-todate literature review. Biomed Res Int. 2016;2016:3285179.

107. Matthijs G, Souche E, Alders M, et al. Guidelines for diagnostic next-generation sequencing. Eur J Hum Genet. 2016;24:1515-15.

108. Richards S, Aziz N, Bale S, et al. Standards and guidelines for the interpretation of sequence variants: a joint consensus recommendation of the american college of medical genetics and genomics and the association for molecular pathology. Genet Med. 2015;17:405-23.

109. HGVS: Human Genome Variation Society. 2017. http://va rnomen.hgvs.org (Accessed 14 Sep 2017).

110. Claustres M, Kožich V, Dequeker E, et al. Recommendations for reporting results of diagnostic genetic testing (biochemical, cytogenetic and molecular genetic). Eur $\mathrm{J}$ Hum Genet. 2014;22:160-70.

111. Kamps R, Brandão R, Bosch B, et al. Next-generation sequencing in oncology: genetic diagnosis, risk prediction and cancer classification. Int J Mol Sci. 2017;18:308.

112. Fragouli E, Wells D. Aneuploidy in the human blastocyst. Cytogenet Genome Res. 2011;133:149-59.

113. Scott RT, Galliano D. The challenge of embryonic mosaicism in preimplantation genetic screening. Fertil Steril. 2016;105:1150-52.

114. Greco E, Minasi MG, Fiorentino F. Healthy babies after intrauterine transfer of mosaic aneuploid blastocysts. N Engl J Med. 2015;373:2089-90.

115. Albertini DF, Gleicher N. A detour in the quest for oogonial stem cells: methods matter. Nat Med. 2015;21:1126-7.

116. PGDIS. Preimplantation Genetic Diagnosis International Society Position Statement on Chromosome Mosaicism and Preimplantation Aneuploidy Testing at the Blastocyst Stage. 2016. 1-2. http://www.pgdis.org/docs/newsletter_071816.html (Accessed 14 Sep 2017).

117. Maxwell SM, Colls P, Hodes-Wertz B, et al. Why do euploid embryos miscarry? A case-control study comparing the rate of aneuploidy within presumed euploid embryos that resulted in miscarriage or live birth using next-generation sequencing. Fertil Steril. 2016;106:1414-19.e5.

118. Munné S, Cohen J. Advanced maternal age patients benefit from preimplantation genetic diagnosis of aneuploidy. Fertil Steril. 2017; http://oi:10.1016/j.fertnstert.2017.03.015.
119. Gleicher N, Kushnir VA, Barad DH. Preimplantation genetic screening (PGS) still in search of a clinical application: a systematic review. Reprod Biol Endocrinol. 2014;12:22.

120. Murugappan G, Shahine LK, Perfetto CO, Hickok LR, Lathi RB. Intent to treat analysis of in vitro fertilization and preimplantation genetic screening versus expectant management in patients with recurrent pregnancy loss. Hum Reprod. 2016;31:1668-74.

121. Gleicher N, Orvieto R. Is the hypothesis of preimplantation genetic screening (PGS) still supportable? A review. J Ovarian Res. 2017;10:21.

122. Gianaroli L, Magli MC, Pomante A, et al. Blastocentesis: a source of DNA for preimplantation genetic testing. Results from a pilot study. Fertil Steril. 2014;102:1692-9.e6.

123. Magli MC, Pomante A, Cafueri G, et al. Preimplantation genetic testing: polar bodies, blastomeres, trophectoderm cells, or blastocoelic fluid? Fertil Steril. 2016;105:676-83.e5.

124. Zhang Y, Li N, Wang L, et al. Molecular analysis of DNA in blastocoele fluid using next-generation sequencing. J Assist Reprod Genet. 2016;33:637-45.

125. Lin R, Feng G, Shu J, et al. Blastocoele re-expansion time in vitrified-warmed cycles is a strong predictor of clinical pregnancy outcome. J Obstet Gynaecol Res. 2017;43:689-95.

126. Galluzzi L, Palini S, Stefani SDe, et al. Extracellular embryo genomic DNA and its potential for genotyping applications. Futur Sci OA. 2015;1:FSO62.

127. Hammond ER, McGillivray BC, Wicker SM, et al. Characterizing nuclear and mitochondrial DNA in spent embryo culture media: genetic contamination identified. Fertil Steril. 2017;107:220-28.e5.

128. Lo YMD, Corbetta N, Chamberlain PF, et al. Presence of fetal DNA in maternal plasma and serum. Lancet. 1997;350:485-87.

129. Tamminga S, van Maarle M, Henneman L, Oudejans CBM, Cornel MC, Sistermans EA. Maternal plasma DNA and RNA sequencing for prenatal testing. In: Advances in clinical chemistry. 2016; p. 63-102.

130. Van Opstal D, Srebniak MI. Cytogenetic confirmation of a positive NIPT result: evidence-based choice between chorionic villus sampling and amniocentesis depending on chromosome aberration. Expert Rev Mol Diagn. 2016;16:513-20.

131. Drury S, Hill M, Chitty LS. Cell-free fetal DNA testing for prenatal diagnosis. Adv Clin Chem. 2016;76:1-35.

132. Verhoef TI, Hill M, Drury S, et al. Non-invasive prenatal diagnosis (NIPD) for single gene disorders: cost analysis of NIPD and invasive testing pathways. Prenat Diagn. 2016;36:636-42.

133. Gregg AR, Skotko BG, Benkendorf JL, et al. Noninvasive prenatal screening for fetal aneuploidy, 2016 update: a position statement of the American College of Medical Genetics and Genomics. Genet Med. 2016;18:1056-65.

134. Wilson KL, Czerwinski JL, Hoskovec JM, et al. NSGC practice guideline: prenatal screening and diagnostic testing options for chromosome aneuploidy. J Genet Couns. 2013;22:4-15.

135. ISPD: International Society of Prenatal Diagnosis - "Position statement from the chromosome abnormality screening committee on behalf of the board of the International Society for Prenatal Diagnosis. 2015. https://www.ispdhome.org/docs/ISPD/ SocietyStatements/PositionStatement_Current_8Apr2015.pdf (Accessed 14 Sep 2017).

136. Brewer J, Demers L, Musci T. Survey of US obstetrician opinions regarding NIPT use in general practice: implementation and barriers. J Matern Fetal Neonatal Med. 2016;30:1-4.

137. Minear MA, Lewis C, Pradhan S, Chandrasekharan S. Global perspectives on clinical adoption of NIPT. Prenat Diagn. 2015;35:959-67.

138. Bustamante-Aragones A, Perlado-Marina S, Trujillo-Tiebas MJ, et al. Non-invasive prenatal diagnosis in the management of 
preimplantation genetic diagnosis pregnancies. J Clin Med. 2014;3:913-22.

139. Dondorp W, de Wert G, Bombard Y, et al. Non-invasive prenatal testing for aneuploidy and beyond: challenges of responsible innovation in prenatal screening. Eur $\mathrm{J}$ Hum Genet. 2015;23:1592-92.

140. Nuffield Council on Bioethics. Non-invasive prenatal testing: ethical issues. 2017. http://nuffieldbioethics.org/wp-content/ uploads/NIPT-ethical-issues-full-report.pdf (Accessed 14 Sep 2017).

141. Chitty LS, Bianchi DW. Next generation sequencing and the next generation: how genomics is revolutionizing reproduction. Prenat Diagn 2015;35:929-30.

142. Mersy E, Smits LJM, van Winden LAAP, et al. Noninvasive detection of fetal trisomy 21: systematic review and report of quality and outcomes of diagnostic accuracy studies performed between 1997 and 2012. Hum Reprod Update. 2013;19:318-29.

143. Wald NJ, Bestwick JP, Huttly WJ. Improvements in antenatal screening for Down's syndrome. J Med Screen. 2013;20:7-14.

144. Gil M, Accurti V, Santacruz B, Plana M, Nicolaides K. Analysis of cell-free DNA in maternal blood in screening for aneuploidies: updated meta-analysis. Ultrasound Obstet Gynecol. 2017. http:// doi:10.1002/uog. 17484.

145. Norton ME, Wapner RJ. Cell-free DNA analysis for noninvasive examination of trisomy. N Engl J Med. 2015;373:2581-82.

146. Taylor-Phillips S, Freeman K, Geppert J, et al. Accuracy of noninvasive prenatal testing using cell-free DNA for detection of Down, Edwards and Patau syndromes: a systematic review and meta-analysis. BMJ Open 2016;6:e010002.

147. Wald NJ, Huttly WJ, Bestwick JP, Aquilina J, Peregrine E. Reflex antenatal DNA screening for Down syndrome. Prenat Diagn. 2015;35:1154-1154.

148. Gil MM, Revello R, Poon LC, Akolekar R, Nicolaides KH. Clinical implementation of routine screening for fetal trisomies in the UKNHS: cell-free DNA test contingent on results from first-trimester combined test. Ultrasound Obstet Gynecol. 2016;47:45-52.

149. Hill M, Wright D, Daley R, et al. Evaluation of non-invasive prenatal testing (NIPT) for aneuploidy in an NHS setting: a reliable accurate prenatal non-invasive diagnosis (RAPID) protocol. BMC Pregnancy Childbirth. 2014;14:229.

150. Liehr T, Lauten A, Schneider U, Schleussner EWA. Noninvasive prenataltesting - when is it advantageous to apply? Biomed Hub. 2017;2:458432.

151. Amant F, Verheecke M, Wlodarska I, et al. Presymptomatic identification of cancers in pregnant women during noninvasive prenatal testing. JAMA Oncol. 2015;1:814-9.

152. Bianchi DW, Chudova D, Sehnert AJ, et al. Noninvasive prenatal testing and incidental detection of occult maternal malignancies. JAMA. 2015;314:162-9.

153. Salvi S, Gurioli G, De Giorgi U, et al. Cell-free DNA as a diagnostic marker for cancer: current insights. Onco Targets Ther. 2016;9:6549-59.

154. Morris S, Karlsen S, Chung N, Hill M, Chitty LS. Model-based analysis of costs and outcomes of non-invasive prenatal testing for Down's syndrome using cell free fetal DNA in the UK national health service. PLoS One. 2014;9:e93559.

155. Gyselaers W, Hulstaert F, Neyt M. Contingent non-invasive prenatal testing: an opportunity to improve non-genetic aspects of fetal aneuploidy screening. Prenat Diagn. 2015;35:1347-52.

156. Petersen OB, Vogel I, Ekelund C, et al. Potential diagnostic consequences of applying non-invasive prenatal testing: population-based study from a country with existing firsttrimester screening. Ultrasound Obstet Gynecol. 2014;43:265-71.
157. O'Brien BM, Halliday J, Lambert-Messerlian G, Eklund EE, Kloza E, Palomaki GE. Nuchal translucency measurement in the era of prenatal screening for aneuploidy using cell free (cf)DNA. Prenat Diagn. 2017;37:303-05.

158. Palomaki GE, Kloza EM, O’Brien BM, Eklund EE, LambertMesserlian GM. The clinical utility of DNA-based screening for fetal aneuploidy by primary obstetrical care providers in the general pregnancy population. Genet Med. 2017. http:// doi:10.1038/gim.2016.194.

159. Benn P. Expanding non-invasive prenatal testing beyond chromosomes 21, 18, 13, X and Y. Clin Genet. 2016;90:477-85.

160. Rose NC, Benn P, Milunsky A. Current controversies in prenatal diagnosis 1: should NIPT routinely include microdeletions/ microduplications? Prenat Diagn. 2016;36:10-4.

161. Rijnders RJ, van der Schoot CE, Bossers B, de Vroede MA, Christiaens GC. Fetal sex determination from maternal plasma in pregnancies at risk for congenital adrenal hyperplasia. Obstet Gynecol. 2001;98:374-8.

162. Miura K, Higashijima A, Shimada T, et al. Clinical application of fetal sex determination using cell-free fetal DNA in pregnant carriers of X-linked genetic disorders. J Hum Genet. 2011;56:296-9.

163. Donley G, Hull SC, Berkman BE. Prenatal whole genome sequencing: just because we can, should we? Hastings Cent Rep. 2012;42:28-40.

164. Deans Z, Clarke AJ, Newson AJ. For your interest? The ethical acceptability of using non-invasive prenatal testing to test 'purely for information'. Bioethics. 2015;29:19-25.

165. de Wert G, Dondorp W, Bianchi DW. Fetal therapy for Down syndrome: an ethical exploration. Prenat Diagn. 2017;37:222-28.

166. Otten ABC, Smeets HJM. Evolutionary defined role of the mitochondrial DNA in fertility, disease and ageing. Hum Reprod Update. 2015;21:671-89.

167. Richardson J, Irving L, Hyslop LA, et al. Concise reviews: Assisted reproductive technologies to prevent transmission of mitochondrial DNA disease. Stem Cells. 2015;33:639-45.

168. Hellebrekers DMEI, Wolfe R, Hendrickx ATM, et al. PGD and heteroplasmic mitochondrial DNA point mutations: a systematic review estimating the chance of healthy offspring. Hum Reprod Update. 2012;18:341-9.

169. Reznichenko A, Huyser C, Pepper M. Mitochondrial transfer: Implications for assisted reproductive technologies. Appl Transl Genomics. 2016;11:40-47.

170. Wolf DP, Mitalipov N, Mitalipov S. Mitochondrial replacement therapy in reproductive medicine. Trends Mol Med. 2015;21:68-76.

171. McGrath J, Solter D. Nuclear transplantation in the mouse embryo by microsurgery and cell fusion. Science. 1983;220:1300-2.

172. Hyslop LA, Blakeley P, Craven L, et al. Towards clinical application of pronuclear transfer to prevent mitochondrial DNA disease. Nature. 2016;534:383-86.

173. Tachibana M, Sparman M, Sritanaudomchai H, et al. Mitochondrial gene replacement in primate offspring and embryonic stem cells. Nature. 2009;461:367-72.

174. Tachibana M, Amato P, Sparman M, et al. Human embryonic stem cells derived by somatic cell nuclear transfer. Cell 2013;153:1228-38.

175. Tachibana M, Amato P, Sparman M, et al. Towards germline gene therapy of inherited mitochondrial diseases. Nature. 2012;493:627-31.

176. Zhang J, Liu H, Luo S, et al. Live birth derived from oocyte spindle transfer to prevent mitochondrial disease. Reprod Biomed Online. 2017;34:361-68. 
177. Zhang J, Zhuang G, Zeng Y, et al. Pregnancy derived from human zygote pronuclear transfer in a patient who had arrested embryos after IVF. Reprod Biomed Online. 2016;33:529-33.

178. Zhang S-P, Lu C-F, Gong F et al. Polar body transfer restores the developmental potential of oocytes to blastocyst stage in a case of repeated embryo fragmentation. J Assist Reprod Genet. 2017. http://doi:10.1007/s10815-017-0881-y.

179. Palacios-González C. Ethics of mitochondrial replacement techniques: a habermasian perspective. Bioethics. 2017;31:27-36.

180. Nuffield Council on Bioethics. Novel techniques for the prevention of mitochondrial DNA disorders: an ethical review 2012. http://nuffieldbioethics.org/project/mitochondrial-dna-disorders (Accessed 14 Sep 2017).

181. Bredenoord AL, Hyun I. The road to mitochondrial gene transfer: follow the middle lane. Mol Ther 2015;23:975-6.

182. Fogleman S, Santana C, Bishop C, Miller A, Capco DG. CRISPR/Cas9 and mitochondrial gene replacement therapy: promising techniques and ethical considerations. Am J Stem Cells. 2016;5:39-52.

183. Gómez-Tatay L, Hernández-Andreu J, Aznar J. Mitochondrial modification techniques and ethical issues. $\mathrm{J}$ Clin Med. 2017;6:25.

184. Barritt JA, Willadsen S, Brenner C, Cohen J. Cytoplasmic transfer in assisted reproduction. Hum Reprod Update. 2001;7:428-35.

185. White YAR, Woods DC, Takai Y, Ishihara O, Seki H, Tilly JL. Oocyte formation by mitotically active germ cells purified from ovaries of reproductive-age women. Nat Med. 2012;18:413-21.

186. Woods DC, Tilly JL. Autologous germline mitochondrial energy transfer (AUGMENT) in human assisted reproduction. Semin Reprod Med. 2015;33:410-21.

187. Erler P, Sweeney A, Monaghan JR. Regulation of injury-induced ovarian regeneration by activation of oogonial stem cells. Stem Cells. 2017;35:236-47.

188. Diez-Juan A, Rubio C, Marin C, et al. Mitochondrial DNA content as a viability score in human euploid embryos: less is better. Fertil Steril. 2015;104:534-41.e1.

189. Fragouli E, Wells D. Mitochondrial DNA assessment to determine oocyte and embryo viability. Semin Reprod Med. 2015;33:401-09.

190. Victor AR, Brake AJ, Tyndall JC, et al. Accurate quantitation of mitochondrial DNA reveals uniform levels in human blastocysts irrespective of ploidy, age, or implantation potential. Fertil Steril. 2017;107:34-42.e3.

191. St. John JC. Mitochondrial DNA copy number and replication in reprogramming and differentiation. Semin Cell Dev Biol. 2016;52:93-101.

192. Stigliani S, Persico L, Lagazio C, Anserini P, Venturini PL, Scaruffi P. Mitochondrial DNA in Day 3 embryo culture medium is a novel, non-invasive biomarker of blastocyst potential and implantation outcome. Mol Hum Reprod. 2014;20:1238-46.

193. Hammoud SS, Cairns BR, Carrell DT. Analysis of gene-specific and genome-wide sperm DNA methylation. Methods Mol Biol 2013;927:451-458.

194. Seisenberger S, Peat JR, Hore TA, Santos F, Dean W, Reik W. Reprogramming DNA methylation in the mammalian life cycle: building and breaking epigenetic barriers. Philos Trans R Soc Lond B Biol Sci. 2013;368:20110330.

195. Smith ZD, Chan MM, Humm KC, et al. DNA methylation dynamics of the human preimplantation embryo. Nature. 2014;511:611-15.

196. Kelsey G, Feil R. New insights into establishment and maintenance of DNA methylation imprints in mammals. Philos Trans R Soc B Biol Sci. 2012;368:20110336-20110336.
197. Smallwood SA, Kelsey G. De novo DNA methylation: a germ cell perspective. Trends Genet 2012;28:33-42.

198. Fleming TP, Kwong WY, Porter R, et al. The Embryo and Its Future1. Biol Reprod. 2004;71:1046-54.

199. Feil R, Fraga MF. Epigenetics and the environment: emerging patterns and implications. Nat Rev Genet. 2012;13:97-109.

200. Hammoud SS, Nix DA, Zhang H, Purwar J, Carrell DT, Cairns BR. Distinctive chromatin in human sperm packages genes for embryo development. Nature. 2009;460:473-8.

201. Krausz C, Sandoval J, Sayols S, et al. Novel insights into DNA methylation features in spermatozoa: stability and peculiarities. PLoS One. 2012;7:e44479.

202. Clarke HJ, Vieux K-F. Epigenetic inheritance through the female germ-line: The known, the unknown, and the possible. Semin Cell Dev Biol. 2015;43:106-16.

203. Smallwood SA, Tomizawa S-I, Krueger F, et al. Dynamic CpG island methylation landscape in oocytes and preimplantation embryos. Nat Genet. 2011;43:811-4.

204. Gifford WD, Pfaff SL, Macfarlan TS. Transposable elements as genetic regulatory substrates in early development. Trends Cell Biol. 2013;23:218-26.

205. Zamudio N, Barau J, Teissandier A, et al. DNA methylation restrains transposons from adopting a chromatin signature permissive for meiotic recombination. Genes Dev. 2015;29:1256-70.

206. Hancks DC, Kazazian HH. Roles for retrotransposon insertions in human disease. Mob DNA. 2016;7:9.

207. Sunde A, Brison D, Dumoulin J, et al. Time to take human embryo culture seriously. Hum Reprod. 2016;31:2174-82.

208. van Montfoort APA, Hanssen LLP, de Sutter P, Viville S, Geraedts JPM, de Boer P. Assisted reproduction treatment and epigenetic inheritance. Hum Reprod Update. 2012;18:171-97.

209. Bunkar N, Pathak N, Lohiya NK, Mishra PK. Epigenetics: A key paradigm in reproductive health. Clin Exp Reprod Med. 2016;43:59.

210. Ghosh J, Mainigi M, Coutifaris C, Sapienza C. Outlier DNA methylation levels as an indicator of environmental exposure and risk of undesirable birth outcome. Hum Mol Genet. 2016;25:123-9.

211. de Waal E, Mak W, Calhoun S, et al. In vitro culture increases the frequency of stochastic epigenetic errors at imprinted genes in placental tissues from mouse concepti produced through assisted reproductive technologies. Biol Reprod. 2014;90:22.

212. Pennisi E. The CRISPR Craze. Science. 2013;341:833-36.

213. Vassena R, Heindryckx B, Peco R, et al. Genome engineering through CRISPR/Cas9 technology in the human germline and pluripotent stem cells. Hum Reprod Update. 2016;22:411-9.

214. Liang $\mathrm{P}, \mathrm{Xu} \mathrm{Y}$, Zhang $\mathrm{X}$, et al. CRISPR/Cas9-mediated gene editing in human tripronuclear zygotes. Protein Cell 2015;6:363-72.

215. Kang $\mathrm{X}, \mathrm{He} \mathrm{W}$, Huang $\mathrm{Y}$, et al. Introducing precise genetic modifications into human 3PN embryos by CRISPR/Cas-mediated genome editing. J Assist Reprod Genet. 2016;33:581-8.

216. Ishii T. Reproductive medicine involving genome editing: clinical uncertainties and embryological needs. Reprod Biomed Online. 2017;34:27-31.

217. Ma H, Marti-Gutierrez N, Park SW, Wu J, Lee Y, Suzuki K, Koski A, Ji D, Hayama T, Ahmed R, Darby H, Van Dyken C, Li Y, Kang E, Park AR, Kim D, Kim ST, Gong J, Gu Y, Xu X, Battaglia D, Krieg SA, Lee DM, Wu DH, Wolf DP, Heitner SB, Belmonte JC, Amato P, Kim JS, Kaul S, Mitalipov S. Correction of a pathogenic gene mutation in human embryos. 2149 Nature. 2017;548:413-9. https://doi.org/10.1038/nature23305

218. Strong A, Musunuru K. Genome editing in cardiovascular diseases. Nat Rev Cardiol. 2016;14:11-20. 
219. Ormond KE, Mortlock DP, Scholes DT, Bombard Y, Brody LC, Faucett WA, Garrison NA, Hercher L, Isasi R, Middleton A, Musunuru K, Shriner D, Virani A, Young CE. Human Germline Genome Editing. Am J Hum Genet. 2017;101(2):167-176. https://doi.org/10.1016/j.ajhg.2017.06.012

220. Evitt NH, Mascharak S, Altman RB. Human germline CRISPRcas modification: toward a regulatory framework. Am J Bioeth. 2015; 15:25-29.

221. Hildt E. Human germline interventions-think first. Front Genet. 2016;7:81
222. Lunshof JE. Human germ line editing-roles and responsibilities. Protein Cell. 2016;7:7-10.

223. Nuffield Council on Bioethics - Genome editing: an ethical review 2016. http://nuffieldbioethics.org/project/genome-editing/ ethical-review-published-september-2016 (Accessed 14 Sep 2017).

224. Sherkow JS. CRISPR: Pursuit of profit poisons collaboration. Nature. 2016;532:172-3.

225. Walton D. The slippery slope argument in the ethical debate on genetic engineering of humans. Sci Eng Ethics. 2016. https://doi. org/10.1007/s11948-016-9861-3.

\section{Affiliations}

J.C. Harper ${ }^{1} \cdot$ K. Aittomäki $i^{2}$ P. Borry ${ }^{3} \cdot$ M.C. Cornel $\mathbb{1}^{4} \cdot$ G. de Wert ${ }^{5} \cdot$ W. Dondorp $\mathbb{D i D}^{5} \cdot$ J. Geraedts ${ }^{6} \cdot$ L. Gianaroli ${ }^{7}$. K. Ketterson ${ }^{8} \cdot$ I. Liebaers ${ }^{9,13} \cdot$ K. Lundin ${ }^{10} \cdot$ H. Mertes ${ }^{11} \cdot$ M. Morris ${ }^{12} \cdot$ G. Pennings ${ }^{11} \cdot$ K. Sermon ${ }^{13} \cdot$ C. Spits ${ }^{13}$. S. Soini ${ }^{14}$ - A.P.A. van Montfoort ${ }^{15} \cdot$ A. Veiga ${ }^{16,17} \cdot$ J.R. Vermeesch ${ }^{18} \cdot$ S. Viville ${ }^{19,20} \cdot$ M. Macek Jr. $\mathbb{1}^{21}$ on behalf of the European Society of Human Reproduction and Embryology and European Society of Human Genetics

1 Institute for Women's Health, University College London, London, UK

2 Laboratory of Genetics, Helsinki University Hospital, Helsinki, Finland

3 Department of Public Health and Primary Care, Centre for Biomedical Ethics and Law, KU Leuven, Leuven, Belgium

4 Department of Clinical Genetics, Section Community Genetics, Amsterdam Public Health Research Institute, VU University Medical Center, Amsterdam, The Netherlands

5 Department of Health, Ethics and Society, Research Schools CAPHRI and GROW, Maastricht University, Maastricht, The Netherlands

6 Department Genetics and Cell Biology, GROW School for Oncology and Developmental Biology, Maastricht University Medical Center, Maastricht, The Netherlands

7 S.I.S.Me.R. Reproductive Medicine Unit, Bologna, Italy

8 Althea Science, Inc., Livingston, NJ, USA

9 Center for Medical Genetics, UZ Brussels, Brussels, Belgium

10 Reproductive Medicine, Sahlgrenska University Hospital, Göteborg, Sweden

11 Bioethics Institute Ghent, Department of Philosophy and Moral
Science, Ghent University, Ghent, Belgium

12 Synlab Genetics, Lausanne, Switzerland

13 Research Group Reproduction and Genetics, Vrije Universiteit Brussel, Brussels, Belgium

14 Helsinki Biobank, Helsinki University Central Hospital, Helsinki, Finland

15 IVF Laboratory, Department of Obstetrics \& Gynaecology, Maastricht University Medical Center, Maastricht, The Netherlands

16 Barcelona Stem Cell Bank, Centre of Regenerative Medicine in Barcelona, Hospital Duran i Reynals, Barcelona, Spain

17 Reproductive Medicine Service of Dexeus Woman Health, Barcelona, Spain

18 Department of Human Genetics, KU Leuven, Leuven, Belgium

19 Institute of Parasitology and Pathology, University of Strasbourg, Strasbourg, France

20 Laboratory of Genetic Diagnostics, UF3472-Genetics of Infertility, Nouvel Hôpital Civil, Strasbourg, France

21 Department of Biology and Medical Genetics, Charles University -2nd Faculty of Medicine and Motol University Hospital, Prague, Czech Republic 